WHAT DO COLLEGE STUDENT DRINKERS

WANT TO KNOW?

STUDENT PERCEPTIONS OF

ALCOHOL-RELATED FEEDBACK

\author{
By \\ MARY BETH MILLER \\ Bachelor of Arts \\ Westminster College \\ Fulton, Missouri \\ 2009
}

Submitted to the Faculty of the

Graduate College of the

Oklahoma State University

in partial fulfillment of

the requirements for the Degree of

MASTER OF SCIENCE

May 2012 


\section{WHAT DO COLLEGE STUDENT DRINKERS \\ WANT TO KNOW? \\ STUDENT PERCEPTIONS OF \\ ALCOHOL-RELATED FEEDBACK}

Thesis Approved:

Thad R. Leffingwell

Thesis Adviser

Stephanie Sweatt

R. Matt Alderson

Dr. Sheryl A. Tucker

Dean of the Graduate College 


\section{TABLE OF CONTENTS}

Chapter

Page

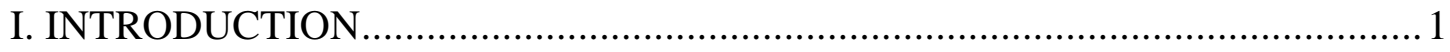

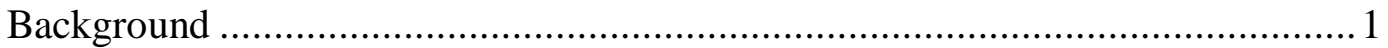

Purpose and Objectives of the Current Study .............................................. 6

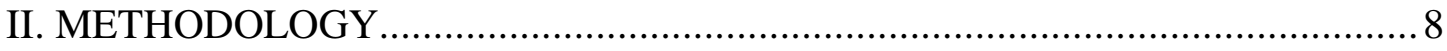

Participant Selection and Recruitment .................................................. 8

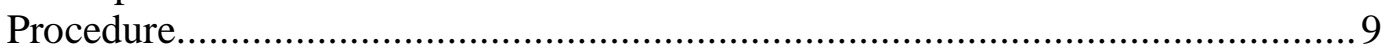

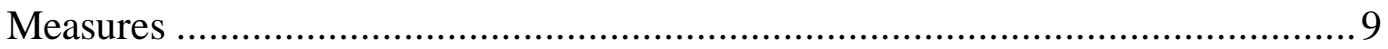

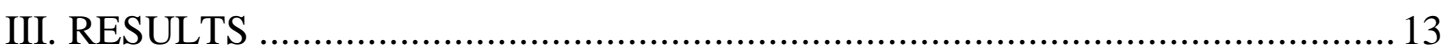

Factor Structure of the Feedback Ratings Questionnaire............................... 13

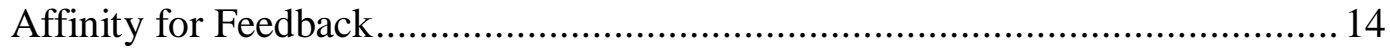

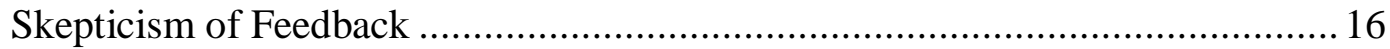

Preferences for Feedback .................................................................. 17

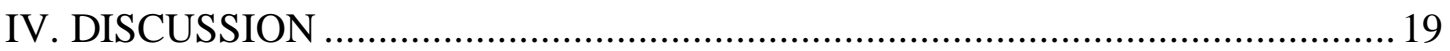

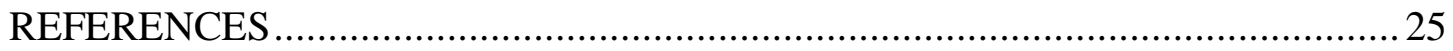

APPENDIX A. REVIEW OF THE LITERATURE ..................................... 32

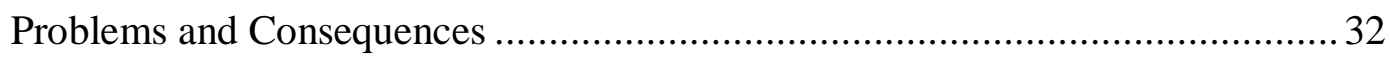

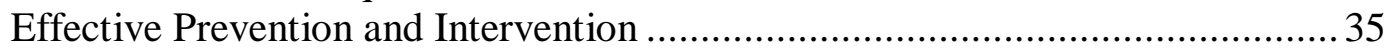

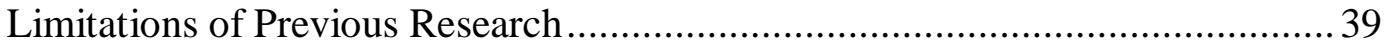

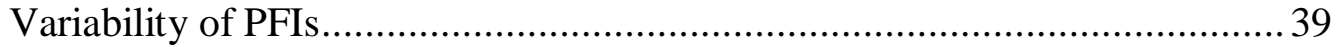

Accounting for Individual Differences .................................................. 49

Student Preferences.................................................................... 51

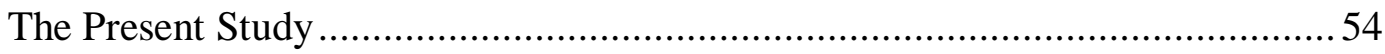

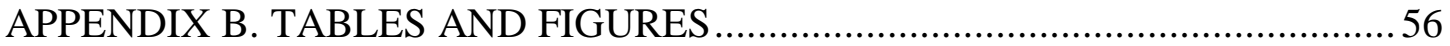




\section{LIST OF TABLES}

Table $\quad$ Page

1. Results of Principle Component Analysis .............................................56

2. Differences in Affinity Ratings between High-Risk and Low-Risk Drinkers ... 59

3. Pairwise Comparisons of Affinity Ratings for High-Risk Drinkers..................60

4. Differences in Affinity Factor Ratings between High-Risk and Low-Risk

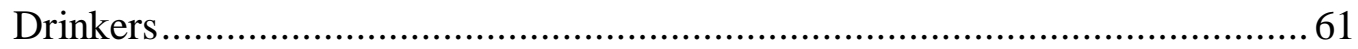

5. Differences in Affinity and Skepticism Ratings between Women $(n=162)$ and Men $(n=235)$ after Controlling for Binge Drinking ............................. 64

6. Student Preferences for Feedback Components .................................... 65 


\section{CHAPTER I}

\section{INTRODUCTION}

Alcohol is one of the most commonly abused drugs in the United States, particularly in college student populations. Findings from national surveys suggest that rates of heavy drinking, driving under the influence, and alcohol-related deaths have all increased from 1998 to the most recent assessment in 2005 (Hingson, Zha, \& Weitzman, 2009). Specifically in 2005, almost half of students report binge drinking (five or more drinks in approximately two hours for males; four or more drinks for females) in the last month; one in three (29\%) reported driving under the influence of alcohol; and approximately 500 students died unintentionally in alcohol-related accidents (Hingson et al., 2009). Although colleges and universities have attempted to prevent and intervene in such problems by implementing a range of programs, the continued increase in rates of risky college drinking suggest that current interventions are not sufficiently effective (Hingson, 2010).

Heavy episodic drinking places college students, their peers, and the institutions with which they are involved at risk of extensive harm (Perkins, 2002). Such drinking patterns have been associated with academic, emotional, physical, interpersonal, and legal problems (Cooper, 2002; Ham \& Hope, 2003; Perkins, 2002; Vik, Carrello, Tate, \& Field, 2000; Testa \& Parks, 1996; Ullman, Karabatsos, \& Koss, 1999b; Weitzman, 2004) as well as increased risk of injury, accidental death, and suicide (Hingson et al., 2009; 
Perkins, 2002). Moreover, high-risk drinking has negative impacts on the student's peers, campus, and society. Adverse consequences endured by peers and the community range from assault and traffic accidents to interrupted studying or sleeping (Ham \& Hope, 2003; Hingson et al., 2009; Perkins, 2002). Colleges and universities are forced to compensate for property damage in residence halls and athletic complexes, to repair public relations, and to meet increased demands on security and administrative personnel (Perkins, 2002). Likewise, heavy drinking incurs a magnitude of preventable healthcare costs in terms of both consequences and treatment (Cortez-Pinto, Gouveia, dos Santos Pinheiro, Costa, Borges, \& Carneiro, 2010; Eigen, 1991).

In response to such findings, colleges and universities have implemented a range of alcohol prevention and intervention programs. Of those that are empirically supported, interventions involving personalized feedback have been some of the most promising to date (Carey, Scott-Sheldon, Carey, \& DeMartini, 2007; Larimer \& Cronce, 2007).

Stemming from motivational and social psychology (Walters \& Neighbors, 2005), personalized feedback interventions (PFIs) are intended to increase students' awareness of drinking habits and costs and to encourage students to thoughtfully consider their use of alcohol and related consequences in hopes that students who do so may alter their use of alcohol in the future. They are employed on approximately $66 \%$ of college campuses (Hingson, 2010) and have been at least moderately effective in reducing drinking and alcohol-related consequences among high-risk drinkers (Carey, Scott-Sheldon et al., 2007; Larimer \& Cronce, 2007; Walters \& Neighbors, 2005). Interestingly enough, however, these interventions differ widely in terms of 'high risk drinking' eligibility criteria, comparison group, follow-up period, and mode of feedback. In addition, the 
content of PFIs varies from a single-page handout clarifying normative drinking patterns among college students to a comprehensive profile of drinking patterns, levels of intoxication, consequences, practical costs, risk factors for future problems, and strategies to limit risk with hyperlinks to a variety of educational websites. Thus, feedback interventions show wide inconsistencies across studies, employing a variety of methods and a broad range of content components and facets.

Similar to the variations of content among PFIs, college students seem to vary in their responses to personalized feedback (Carey, Henson, Carey, \& Maisto, 2007). Though examination of several predicted moderators suggests that personalized feedback seems effective despite a number of individual differences (Baer et al., 1992; Borsari \& Carey, 2005; Chiauzzi, Green, Lord, Thum, \& Goldstein, 2005; Larimer et al., 2001; Marlatt et al., 1998; Walters, Vader, Harris, Field, \& Jouriles, 2009; White, Mun, \& Morgan, 2008), a handful of variables have been found to differentiate between students who do and do not respond well to personalized feedback, two of these being sex and susceptibility to peer pressure.

Several studies have found changes in drinking related to sex, often regardless of treatment condition. The trends, however, are inconsistent. Collins, Carey, and Sliwinski (2002), for example, found that men decreased in drinks per week during the six weeks postintervention while women did not. Murphy et al. (2004) and Saitz et al. (2007) found the opposite, with high-risk women but not men decreasing in weekly drinking at sixmonth and one-month follow-ups, respectively. Juarez, Walters, Daugherty, and Radi (2006) also found that women but not men who received feedback reported reductions in dependency symptoms as compared to those in MI only and control conditions. Though 
they found no difference in drinking quantity, White, Mun, Pugh, and Morgan (2007) also reported that, four months after baseline, women demonstrated a greater reduction than men in alcohol-related problems. Interestingly, women have been found to respond more favorably to responsible drinking messages than men (Pilling \& Brannon, 2007). This may be attributable to the finding that women seem to overestimate normative comparisons (Borsari \& Carey, 2003) and underestimate their own levels of intoxication during moderate episodes of drinking (Mallett, Turrisi, Larimer, \& Mastroleo, 2009) to a greater extent than men. Thus, women may rate feedback, and specifically normative feedback, as more interesting and motivating than do men.

Susceptibility to peer pressure also seems to differentiate between those students who benefit most from PFIs. At three (but not six) months, Neighbors, Larimer, and Lewis (2004) found that personalized feedback was somewhat more effective for participants who drank for social reasons, suggesting that students who drink for social reasons may be more responsive to social comparisons. Lee, Geisner, Lewis, Neighbors, and Larimer (2007) also found that students who drink for social reasons are more strongly driven by their descriptive and injunctive perceptions of close friends' drinking (i.e., they believe their friends drink in risky ways and approve of risky drinking) than those who report low social motives for drinking. Controlled orientation, or the tendency to perceive environmental pressure and lack of true control over one's choices, has also been found to moderate the effect of PFIs specifically on alcohol-related consequences (Neighbors, Lewis, Bergstrom, \& Larimer, 2006). In an earlier study by Knee and Neighbors (2002), the relationship between such extrinsic motives for drinking and actual drinking was mediated by perceived peer pressure from friends. Thus, it is plausible that 
social drinkers and students who are more sensitive to peer pressure may find normative feedback information more compelling than those who are not.

A substantial amount of data regarding the negative effects of high-risk drinking and the methods of its prevention is available in the literature. Despite consistent efforts to reduce binge drinking among college students, the prevalence of heavy drinking in this population has remained stable over the last 15 to 20 years (Hingson et al., 2009). The stability of this drinking pattern may be due in part to use of feedback components that college students, and specifically high risk drinkers, find personally irrelevant or unimportant. Due to inconsistencies across studies, we have been unable to make strong inferences regarding which feedback components are most effective and which are most salient to college students. Research has found that college student drinkers tend not to view college drinking as an important problem, are skeptical of the scientific merit of alcohol risk information, and generally do not view themselves as being in personal risk of alcohol-related problems (Leffingwell, Neumann, Leedy, \& Babitzke, 2007). Thus, interventions designed to provide students with feedback information that they want to know may disarm such defensive responding in high-risk drinkers.

There is some evidence that feedback interventions that are rated as more favorable for a sub-group of students will also be more effective for that group. Specifically, Murphy et al. (2001) found that an in-person PFI was rated as more personally relevant, interesting, and effective by heavier-drinking college students than by more moderate drinkers. At three-month follow-up, high-risk drinkers (either 25 drinks or three heavy drinking nights per week) who received the PFI also demonstrated greater reductions in drinking than those in education or control conditions. Though 
previous studies have examined participant satisfaction, willingness to recommend PFIs to a friend, personal relevance, and effectiveness (Borsari \& Carey, 2000; Borsari \& Carey, 2005; Collins et al., 2002; Murphy et al., 2001; White et al., 2007), each of these studies incorporated different content domains and follow-up periods. When asked specifically which components of the intervention were least or most helpful, students have reported that the $\mathrm{BAC}$ calculations, handouts/feedback profile, and interaction with the counselor were most helpful (Marlatt et al., 1998; White et al., 2007) and that the paperwork and personally irrelevant or already familiar information was least helpful (Marlatt et al., 1998; White et al., 2007). Because none of these studies included the full range of content domains, however, such ratings give us no additional knowledge regarding which domains are most relevant to college students. Thus, the literature warrants additional research regarding students' attitudes toward personalized feedback. PFIs have been one of the most widely studied, empirically supported, and commonly implemented strategies for drinking prevention and intervention on college campuses (Carey, Scott-Sheldon et al., 2007; Larimer \& Cronce, 2007; Hingson, 2010). Yet the content of feedback interventions varies considerably across studies. Such inconsistencies are due in part to a general lack of knowledge regarding which intervention components work best for whom. The present study sought to assess college students' attitudes and preferences for PFI content domains and components in order to identify those messages that most effectively reduce problematic alcohol consumption among high-risk college student drinkers. Based on previous research, it was expected that affinity for feedback would change based on the type of feedback provided and that these patterns of affinity would differ when comparing men and women, high- versus low-risk drinkers, and 
socially-motivated versus non-socially-motivated drinkers. When forced to choose the three feedback components that they most prefer, it was expected that participants would express strongest preference for descriptive normative comparisons; women would prefer all information, but especially reflective normative comparisons, to a greater extent than men; high-risk drinkers would be more interested in descriptive normative comparisons than would low-risk drinkers; and socially-motivated drinkers would be more interested in descriptive and injunctive normative feedback than would participants who drink for other reasons. The results of this study may assist in identifying personalized feedback components that more effectively target certain college student populations. 


\section{CHAPTER II}

\section{METHODOLOGY}

\section{Participant Selection and Recruitment}

Undergraduate students in introductory classes at a large, public university in the Southern Plains were invited to participate in the study as an opportunity to fulfill class requirements. Students were eligible to participate if they were at least 18 years old and reported alcohol use within the last three months. Of the 497 college students that participated in the survey, $30(6 \%)$ were excluded due to missing data ( $\geq 50 \%$ missing). An additional 55 participants $(11 \%)$ were excluded based on self reports of inadequate effort (less than three on a 10-point scale), 12 (2\%) reported not reading the directions, and $3(<1 \%)$ were excluded based on commentary evidence that they had not understood the directions. Thus, the final sample consisted of 397 men $(n=162,41 \%)$ and women $(n$ $=235,59 \%$ ) who had consumed alcohol in the past three months. The self-reported ethnicity of the final sample was $87.9 \%$ Caucasian, 3.5\% Native American, and $8.6 \%$ other ethnicities.

Of the total sample, 228 participants were classified as high-risk drinkers, meaning they reported engaging in at least one binge drinking episode in a typical week. All remaining participants $(n=169)$ were classified as low-risk drinkers. Social drinkers $(n=70)$ reported drinking for social reasons most if not all of the time, while non-socially motivated drinkers $(n=80)$ reported drinking for such reasons some of the time, if ever. 
Participants who reported drinking for social reasons half of the time $(n=247)$ were excluded only from analyses that examined outcome differences based on social drinking status.

\section{Procedure}

All measures were completed remotely online. Participants were then re-directed to a separate webpage on which they recorded their name and contact information in order to receive class credit and were given contact information for the primary researcher in the case that they had questions.

\section{Measures}

Demographics. Participants completed a brief assessment of age, sex, ethnicity, year in school, full- or part-time student status, most recent GPA, Greek affiliation, military involvement, current residence, marital status, and religiosity.

Alcohol consumption. Participants completed the Daily Drinking Questionnaire (DDQ; Collins, Parks, \& Marlatt, 1985) as a face valid measure of typical alcohol consumption. Participants reported the number of alcoholic drinks consumed, over how many hours, on each day of a typical week in the last month. They also estimated the average number of times they had consumed alcohol in the last month and the number of drinks they typically consume on a drinking occasion. They reported frequency of heavy episodic drinking using the Alcohol Consumption Inventory (ACI; Knee \& Neighbors, 2002) by estimating the number of times in the past week/month and in a typical week/month that they consumed five or more drinks in one sitting. Participants were categorized into high-risk and low/moderate-risk drinking groups based on their responses to the item on this measure addressing how many times in an average week 
week they consumed 5 to 10 drinks in one setting. They also reported the number of drinks they consume both during the week (Monday through Thursday) and on the weekends (Friday and Saturday) and compared the quantity of their drinking to that consumed by their friends and other college students. This measure has demonstrated high internal reliability $(\alpha=.96)$ in undergraduate samples (Knee \& Neighbors, 2002).

Negative consequences. The Brief Young Adult Alcohol Consequences Questionnaire (B-YAACQ; Kahler, Strong, \& Read, 2005) is a 24-item measure of alcohol-related consequences that indicates drinking severity within an undergraduate college student population. Participants responded to items such as, "I have driven a car when I knew I had too much to drink to drive safely," "I have woken up in an unexpected place after drinking," and, "I have neglected my obligations to family, work, or school because of drinking" in a yes/no format. Cronbach's $\alpha$ for this scale ranged from .84 to .89 (Kahler et al., 2005).

Social reasons for drinking. The Social and Conformity subscales of the Modified Drinking Motives Questionnaire-Revised (Modified DMQ-R) will be used to assess social motives for drinking. Both sub-scales include five Likert-style items addressing how often students drink for social reasons (e.g., "as a way to celebrate" or "to fit in with a group I like") and have demonstrated high internal consistency (Social, $\alpha=.58-.69$; Conformity, $\alpha=$.74-.91) among undergraduate college students (Grant, Stewart, O’Connor, Blackwell, \& Conrod, 2007). Participants were categorized into social versus non-social drinking groups based on their responses to the Social subscale of this questionnaire. Responses to each of the Social Subscale items were summed and divided by five to produce an average Social Drinking score. Participants with mean scores above 
or equal to three (a response of "most of the time") were classified as social drinkers, and those with mean scores less than or equal to one (a response of "some of the time") were classified as non-social drinkers.

Feedback ratings questionnaire. Participants were given a hypothetical scenario in which a student, who reported consuming 23 drinks per week and experiencing a number of negative consequences related to his/her alcohol consumption, was given 14 personalized feedback messages regarding his/her drinking. Participants were asked to imagine that the feedback provided reflected their personal use of alcohol and to rate their level of agreement with several statements regarding each feedback component. Each component was rated on level of novelty ("Information regarding...would be new information to me"), interest (e.g., "This information would be interesting to me"), personal relevance ("This information would be personally relevant to me"), motivation ("This information would motivate me to cut back on my drinking"), impact on intent to reduce alcohol consumption ("Based on this information, I would cut back on my drinking”), and credibility (“I would be skeptical of this information"). As a reliability measure, participants rated on a 10-point scale how carefully they had read the instructions at the beginning of the questionnaire $(1=$ didn't read; $10=$ as carefully as possible). An image choice sample of the nine feedback components currently offered in personalized feedback interventions (descriptive norms, injunctive norms, reflective norms, BAC, didactic information, strategies to limit risk, risk factors, consequences, and practical costs) was then presented, and participants chose the three of these components that they would choose to view if they could see no others. 
Perceived norms. Participants reported the average number of standard drinks that they believe their closest male/female friends as well as the typical male/female students at their college consume on each day of a typical week (Drinking Norms Rating Form; Baer, Stacy, \& Larimer, 1991). They also reported the way in which they believe their friends would respond to four high-risk drinking behaviors (drinking every weekend, drinking daily, driving after drinking, and drinking enough to pass out) as well as how much alcohol students of the opposite sex would like their friends, dates, and sexual partners to consume on a typical drinking occasion.

Actual injunctive norms. Participants indicated to what extent they approve of high-risk drinking behaviors using a four-item measure of injunctive norms (Baer, 1994). On a scale from one (strong disapproval) to seven (strong approval), participants rated the way they would respond to their friends' drinking alcohol every weekend, drinking alcohol daily, driving after drinking alcohol, and drinking enough alcohol to pass out. Participants also reported the typical and maximum number of drinks they would want their friends, dates, and sexual partners to drink on a typical drinking occasion (LaBrie, Cail, Hummer, Lac, \& Neighbors, 2009). 


\section{CHAPTER III}

\section{RESULTS}

Factor Structure of the Feedback Ratings Questionnaire. An exploratory principal component analysis of the six items of the Feedback Ratings Questionnaire (FRQ) was conducted on one, randomly selected content component (alcohol-related consequences) to determine if the first five items of the FRQ could be aggregated to reflect a single factor within each component. Examination of the scree plot suggested a two-factor solution that accounted for 80 percent of the total variance. Of the remaining factors, no single factor accounted for more than 10 percent of the total variance. Thus, two factors were subjected to a varimax rotation. Five items loaded on the first factor with coefficients of .73 or greater (and no cross-loadings greater than .35), and one item loaded on the second factor with a coefficient of .97 (cross-loading $=.09$ ). The first five items loaded strongly on the first factor and seemed to represent a general liking or not liking of the feedback components. Thus, these scores were added together to create a single "affinity" score. The second, single-item facet reflects cynicism regarding the feedback information and will be utilized as a variable of "skepticism."

The two-factor structure of the FRQ was subsequently tested by repeating the principal component analysis for each of the remaining 13 feedback components (see Table 1 in Appendix A for results for each factor). The two-factor structure was fairly consistent across all 14 feedback components. Cronbach's $\alpha$ for the five-item factor ranged from .83 
to .93 , suggesting strong reliability for the affinity factor. Based on these analyses, it was determined that the first five items of the FRQ reflect the best measure of overall liking for each component, and summing these items to create an overall affinity variable is justified.

Affinity for Feedback. A repeated measures ANOVA was used to determine differences in overall affinity for feedback components. Bonferroni's adjustment $(\alpha=$ .004) was used to control for inflation in Type I error rates in post-hoc tests. Mauchly's test indicated that the assumption of sphericity was violated for the main effect of feedback, $\chi 2(90)=991.98, p<.001$. Therefore, degrees of freedom were corrected using Greenhouse-Geisser estimates of sphericity $(\varepsilon=.66)$. Affinity for the entire sample was significantly affected by type of feedback, $F(8.58,3370.61)=87.22, p<.001, \eta^{2}=.18$, with strongest affinity for practical costs $(M=2.73, S D=2.32)$ and lowest affinity for injunctive normative comparisons $(M=.33, S D=.62)$. Means and standard deviations for all affinity ratings are depicted in Table 2 .

High-risk drinking was defined as engaging in at least one binge drinking episode in a typical week. Affinity for feedback differed significantly as a function of risky drinking status, $F(1,393)=13.39, p<.001, \eta^{2}=.03$, with high-risk drinkers $(n=228)$ reporting lower overall affinity for all feedback components $(M=1.48, S D=1.87)$ than low-risk drinkers $(n=169 ; M=2.30, S D=1.85)$. They also demonstrated a slightly different pattern of affinity ratings across components than did low-risk drinkers, as evidenced by the significant interaction term of the affinity main effect, $F(8.58,3370.61)$ $=1.99, p=.039, \eta^{2}=.01$. After correcting for Type I error using Bonferroni's adjustment, high-risk drinkers reported significantly less affinity than low-risk drinkers 
for feedback regarding descriptive norms, injunctive norms, risk factors for future problems, and cognitive functioning. Means, standard deviations, and results of group comparisons are depicted in Table 2.

To inform the development of future personalized feedback interventions, differences in affinity specifically among high-risk drinkers were examined using mean pairwise comparisons. Overall, high-risk drinkers demonstrated greater affinity for practical costs $(M=2.55, S D=2.31)$, genetic risk $(M=2.42, S D=2.26)$, and effects of alcohol on liver functioning $(M=2.34, S D=2.25)$ than for all other feedback components (see Table 3 for results of pairwise comparisons). In addition, each item comprising the affinity scores was examined separately for high- and low-risk drinkers (see Table 4). In comparing these groups, high-risk drinkers rated the majority of feedback components (BAC, risk factors, cognitive functioning, descriptive norms, percentile rankings, reflective norms, the drinking profile, injunctive norms, didactic information, and strategies) as significantly less motivating and less likely to impact intent to change drinking behavior than did their lower-risk peers $(\alpha=.004)$. They also reported a number of components (risk factors, cognitive functioning, and injunctive norms) as less novel than did low-risk drinkers, and they expressed less interest in information related to risk factors for future problems. No differences in ratings of personal relevance were found using Bonferroni's adjustment. Means, standard deviations, and $t$-values for these analyses are depicted in Table 4 .

Affinity for feedback also differed as a function of sex. However, women in the current sample $(n=235)$ reported engaging in significantly fewer heavy-drinking episodes $(M=.83, S D=1.01)$ than men $(M=1.25, S D=1.14), t(1,395)=-3.81, p<$ 
.001 . Thus, a repeated measures ANCOVA was conducted to determine the effect of sex on affinity ratings while controlling for participant drinking status. The covariate, binge drinking in a typical week, was significantly related to affinity for feedback, $F(1,394)=$ $30.03, p<.001, \eta^{2}=.07$. However, sex also had a significant effect on affinity ratings, $F(1,394)=27.02, p<.001, \eta^{2}=.06$. Consistent with Hypothesis 2, women reported stronger affinity for all feedback components $(M=2.22, S D=1.76)$ than did men $(M=$ $1.27, S D=1.77)$. They reported significantly greater affinity for reflective normative comparisons, $F(1,394)=10.19, p=.002, \eta^{2}=.03$. After adjusting for Type I error, women also reported significantly greater affinity than men for feedback regarding personal drinking, descriptive norms, percentile rankings, injunctive norms, practical costs of drinking, and alcohol-related cognitive functioning. Means, standard deviations, and $F$-values for these analyses are depicted in Table 5.

Independent samples $t$-tests revealed significant differences between social and non-social drinkers in binge drinking in a typical week, $t(148)=-9.56, p<.001$. After controlling for risky drinking status, social drinking status did not have a significant impact on affinity for feedback, $F(2,148)=.16, p=.85$.

Skepticism of Feedback. Three repeated measures ANOVAs were also used to determine differences in skepticism for feedback components, again using Bonferroni's adjustment $(\alpha=.004)$ to control for inflation in Type I error rates in post hoc tests. In all ANOVAs, Mauchly's test indicated that the assumption of sphericity was violated for the main effect of skepticism, and degrees of freedom were corrected using GreenhouseGeisser estimates of sphericity. The skepticism score for the entire sample, using risky drinking status as the between-subjects factor, was significantly affected by the type of 
feedback provided, $F(9.63,3785.16)=26.27, p<.001, \eta^{2}=.06$. Examination of mean ratings for the entire sample revealed greatest skepticism for percentile rankings $(M=$ $.18, S D=2.93)$ and least skepticism for didactic information $(M=-1.46, S D=3.01)$. Skepticism did not differ as a function of risky drinking status, $F(1,393)=1.08$, $n s$. After controlling for binge drinking status, skepticism for feedback also did not differ based on social drinking status, $F(1,147)=.87, n s$. However, significant differences in skepticism were found between men and women after controlling for binge drinking status, $F(1,394)$ $=5.78, p=.017, \eta^{2}=.01$. Men reported significantly greater skepticism of feedback regarding the practical costs of drinking, alcohol-related cognitive functioning, and level of genetic risk (see Table 5).

Preferences for Feedback. Consistent with hypotheses, participants demonstrated the strongest preference for descriptive normative comparisons, with 58 percent of students ranking the descriptive norm as one of their top three choices of personalized feedback information. Fifty-six percent also chose feedback regarding the personalized costs of their drinking. The highest subsequent percentage was BAC (34\%).

A chi-square test of association was conducted to examine differences in preferences across risky drinking status, sex, and social drinking status. No correction was made for Type I error. There was a significant association between sex and preference for descriptive norms, $\chi^{2}(1)=4.70, p=.030$, with the odds of preferring descriptive norms being 1.58 times higher for females than for males. There were no significant differences between sexes for preferences of any other feedback component. There was also a significant association between social drinking status and preference for practical costs, $\chi^{2}(1)=6.46, p=.011$. The odds of preferring practical cost information 
were 2.34 times higher for social drinkers than for non-social drinkers. No other significant associations were found between social drinking status and preferences for feedback, and no significant associations were found between risky drinking status and preferences.

Contrary to hypotheses, there were no significant differences in the proportion of low- and high-risk drinkers who preferred the descriptive normative comparison, the proportion of males and females who preferred reflective normative comparisons, or the proportion of social and non-social drinkers who preferred descriptive norms. In fact, trends in preferences were typically in the opposite direction of those predicted, such that a larger proportion of low-risk than high-risk drinkers seemed to prefer the descriptive normative comparison ( $62 \%$ and $55 \%$, respectively), a larger percentage of males (31\%) than females $(24 \%)$ ranked reflective norms within their top three preferences, and a larger percentage of non-social (35\%) than social drinkers $(26 \%)$ reported a preference for injunctive normative information. However, the pattern of preferences for descriptive normative information between socially motivated and non-socially motivated drinkers did parallel hypotheses, with a slightly larger percentage of social than non-social drinkers preferring descriptive norms (57 and 54\%, respectively). 


\section{CHAPTER IV}

\section{DISCUSSION}

This study provides a number of findings that are relevant to the development of effective personalized feedback interventions for high-risk drinking college students. High-risk drinkers demonstrated greater affinity for feedback regarding the practical costs of their drinking, their personal genetic risk for alcohol problems, and the effects of drinking on their liver functioning than for all other types of feedback. Of the feedback components commonly used in feedback interventions, high-risk drinkers rated the practical costs of their drinking as the most novel, interesting, and personally relevant feedback information. They also suggested it has the greatest impact on their motivation and intent to change their drinking behavior, and it is the most commonly selected component of feedback when they are asked to choose the three pieces of information they would prefer above all others. Conversely, they reported least affinity for feedback regarding the frequency and quantity of their drinking (profile), their peers' approval of high-risk drinking (injunctive norms), didactic information, and strategies to reduce drinkingrelated risk. They rated didactic information as the least novel and personally relevant information and strategies to reduce alcohol-related risk as the least interesting and the least likely to impact motivation and intent to change. However, the list of strategies to reduce risk was also the feedback component of which they were least skeptical. These findings may guide the development of future feedback interventions, which will likely 
benefit from capitalizing on information that college students perceive as relevant and important.

Perhaps more important than this pattern of ratings among high-risk drinkers, however, is the way in which it compares to the pattern of ratings among lower-risk drinkers. College students who drink heavily reported significantly less affinity for all feedback components than did their lower-risk peers (with the exception of practical costs, for which affinity was statistically equivalent across groups). Examination of the different factors that comprised these affinity scores suggests that high-risk drinkers find the majority of feedback components significantly less motivating and likely to impact their intent to change. They also rated the majority of feedback components as less personally relevant, less interesting, and less novel than did their lower-risk peers. This replicates the results of a previous study (Leffingwell et al., 2007), in which high-risk college student drinkers rated college student drinking as less personally relevant and a less important problem than did lighter drinking students. It is possible that high-risk drinkers either dismiss or respond defensively to this information. Previous authors (Sweeny, Melnyk, Miller, \& Shepperd, 2010) have suggested people may avoid information that requires a change in beliefs, indicates an undesired change in behavior, or causes unpleasant (or less pleasant) emotions. Though the evidence for these responses has been well-documented, none of the studies in the Sweeny and colleagues (2010) review specifically targeted alcohol consumption among college students. Thus, future studies may investigate which of these factors, if not all three, plays a role in the defensively biased processing of personalized alcohol feedback among college students. 
Contradictory to previous findings (Leffingwell et al., 2007), college student drinkers in the current sample did not report an overall tendency to be skeptical of personalized feedback. In fact, the majority of skepticism ratings were negative, suggesting participants disagreed with the statement, "I would be skeptical of this information." Though it is encouraging to see that, on average, college students do not seem to disregard the scientific merit of information provided in personalized feedback, they did report skepticism of feedback regarding descriptive normative comparisons, percentile rankings, and reflective normative information; and the standard deviations surrounding these scores suggest that a number of students may be highly skeptical of such information. Because descriptive normative comparisons (and corresponding percentile rankings) are utilized in essentially all personalized feedback profiles, it is important for researchers to be aware of the possibility that many high-risk drinkers may be skeptical of this information. This finding, in conjunction with the above-mentioned tendency for high-risk drinkers to respond defensively to risk-related information, indicates that it may be beneficial to openly acknowledge the source of normative information provided in personalized feedback interventions. Future studies should examine whether doing so reduces skepticism among high-risk drinkers.

It is also worth noting that women responded significantly more favorably to all personalized feedback components than did men. While data regarding the differential efficacy of personalized feedback interventions for men and women is inconclusive, these findings suggest a need to complement current interventions with information that may target specific genders. Women reported being significantly more interested in essentially all components (with the exception of BAC levels) than did men, and they rated the 
majority of components as being more personally relevant. More importantly, they rated each component as being significantly more likely to impact their motivation and intent to change and were less skeptical of several components. This may suggest that men may dismiss risk-related information to a greater extent than women. However, men also reported strongest affinity for feedback components that are not currently incorporated in the majority of personalized feedback interventions (i.e., genetic risk for alcohol problems and effects of alcohol on liver functioning). Thus, it may be that our current interventions do not utilize information that college men find important.

The present study had several limitations that should be considered when interpreting results. Rather than providing truly personalized feedback to participants, the current study utilized a hypothetical scenario in which participants were asked to imagine that the information provided reflected their use of alcohol and to respond as if this were their personal profile. While data were screened carefully with several validity questions, we relied on the honesty of participants in determining their comprehension of directions and perceptions of feedback. Similarly, we lack complete information on the psychometric properties of the new Feedback Ratings Questionnaire (FRQ). Though the five affinity items demonstrated strong internal consistency and were based on items used in previous studies of personalized feedback interventions, the test-retest reliability of the measure is unknown. It is also possible that the single skepticism item was not a reliable or valid measure of participant skepticism of feedback. Thus, future studies may assess the psychometrics of the FRQ more in depth. However, using an abbreviated or modified version of the FRQ in future studies may determine if self-reported ratings and preferences correlate with actual changes in drinking behavior. 
The demographics of our sample may also have affected study outcomes. First, the limited number of low-risk, socially-motivated drinkers in our sample prevented us from generating hypotheses regarding the types of feedback information that may target students who drink in response to social pressure or expectations. In attempting to differentiate between students who do and do not drink for social reasons, it was found that 66 percent of high-risk drinkers reported drinking for social reasons at least half of the time. Thus, it may be more useful in future studies to assess for perceptions of peer pressure or controlled orientation (Knee \& Neighbors, 2002; Neighbors et al., 2006) rather than for socially motivated drinking. The current study also included fewer African American and a slightly larger number of Native American students than may be expected given the demographics of the campus on which this study was conducted. Despite these limitations, the current study yielded a number of findings that have important implications in the prevention of high-risk drinking on college campuses. To our knowledge, this is the first study to thoroughly document students' preferences for the different components commonly included in personalized feedback interventions. Though interventions seem to be effective regardless of the components included, greater consistency among personalized feedback interventions would allow researchers to identify those components that are the necessary and sufficient elements of high-risk drinking prevention. The current study generates hypotheses regarding which of these components may increase the efficacy of current feedback interventions. The demonstrated differences in preferences and affinity for such information suggest that interventions may need to disarm defensive responding in high-risk drinkers prior to providing feedback. Moreover, it may be helpful to tailor interventions for men and 
women somewhat separately in order to increase favorable ratings of feedback among male college students. Incorporating information that students find relevant to their lives may increase the efficacy of interventions for high-risk drinking and may help reduce alcohol-related problems on college campuses. 


\section{REFERENCES}

Baer, J. S. (1994). Effects of college residence on perceived norms for alcohol consumption: An examination of the first year in college. Psychology of Addictive Behaviors, 8, 43-50. doi: 10.1037/0893-164X.8.1.43

Baer, J. S., Marlatt, G. A., Kivlahan, D. R., Fromme, K., Larimer, M. E., \& Williams, E. (1992). An experimental test of three methods of alcohol risk reduction with young adults. Journal of Consulting and Clinical Psychology, 60, 974-979. doi: 10.1037/0022-006X.60.6.974

Baer, J. S., Stacy, A., \& Larimer, M. (1991). Biases in the perception of drinking norms among college students. Journal of Studies on Alcohol and Drugs, 52(6), 580586.

Borsari, B., \& Carey, K. B. (2000). Effects of a brief motivational intervention with college student drinkers. Journal of Consulting and Clinical Psychology, 68, 728733. doi: 10.1037/0022-006X.68.4.728

Borsari, B., \& Carey, K. B. (2003). Descriptive and injunctive norms in college drinking: A meta-analytic integration. Journal of Studies on Alcohol, 64(3), 331-341.

Borsari, B., \& Carey, K. B. (2005). Two brief alcohol interventions for mandated college students. Psychology of Addictive Behaviors, 19, 296-302. doi: 10.1037/0893164X.19.3.296 
Carey, K. B., Henson, J. M., Carey, M. P., \& Maisto, S. A. (2007). Which heavy drinking college students benefit from a brief motivational intervention? Journal of Consulting and Clinical Psychology, 75, 663-669. doi: 10.1037/0022006X.75.4.663

Carey, K. B., Scott-Sheldon, L. A., Carey, M. P., \& DeMartini, K. S. (2007). Individuallevel interventions to reduce college student drinking: A meta-analytic review. Addictive Behaviors, 32, 2469-2494. doi: 10.1016/j.addbeh.2007.05.004

Chiauzzi, E., Green, T. C., Lord, S., Thum, C., \& Goldstein, M. (2005). My student body: A high-risk drinking prevention web site for college students. Journal of American College Health, 53(6), 263-274.

Collins, R. L., Parks, G. A., \& Marlatt, G. A. (1985). Social determinants of alcohol consumption: The effects of social interaction and model status on the selfadministration of alcohol. Journal of Consulting and Clinical Psychology, 53, 189-200. doi: 10.1037/0022-006X.53.2.189

Collins, S. E., Carey, K. B., \& Sliwinski, M. J. (2002). Mailed personalized normative feedback as a brief intervention for at-risk college drinkers. Journal of Studies on Alcohol, 63(5), 559-567.

Cooper, M. L. (2002). Alcohol use and risky sexual behavior among college students and youth: Evaluating the evidence. Journal of Studies on Alcohol, 14, 101-117.

Cortez-Pinto, H., Gouveia, M., dos Santos Pinheiro, L., Costa, J., Borges, M, \& Carneiro, A. V. (2010). The burden of disease and the cost of illness attributable to alcohol drinking - Results of a national study. Alcoholism: Clinical and Experimental Research, 34(8), 1442-1449. 
Eigen, L. D. (1991). Alcohol practices, policies, and potentials of American colleges and universities: An OSAP White paper. Rockville, MD: National Clearinghouse for Alcohol and Drug Information.

Grant, V. V., Stewart, S. H., O’Connor, R. M., Blackwell, E., \& Conrod, P. J. (2007). Psychometric evaluation of the five-factor Modified Drinking Motives Questionnaire - Revised in undergraduates. Addictive Behaviors, 32, 2611-2632. doi: 10.1016/j.addbeh.2007.07.004

Ham, L. S., \& Hope, D. A. (2003). College students and problematic drinking: A review of the literature. Clinical Psychology Review, 23,719-759. doi:10.1016/S02727358(03)00071-0

Hingson, R. W. (2010). Magnitude and prevention of college drinking and related problems. Alcohol Research \& Health, 33(1-2), 45-54.

Hingson, R. W., Zha, W., \& Weitzman, E. R. (2009). Magnitude of and trends in alcoholrelated mortality and morbidity among U.S. college students ages 18-24, 19982005. Journal of Studies on Alcohol and Drugs, 16, 12-20.

Juarez, P., Walters, S. T., Daugherty, M., \& Radi, C. (2006). A randomized trial of motivational interviewing and feedback with heavy drinking college students. Journal of Drug Education, 36, 233-246. doi: 10.2190/753N-8242-727T-G63L

Kahler, C. W., Strong, D. R., \& Read, J. P. (2005). Toward efficient and comprehensive measurement of alcohol problems continuum in college students: The brief young adult alcohol consequences questionnaire. Alcoholism: Clinical and Experimental Research, 29, 1180-1189. doi: 10.1097/01.ALC.0000171940.95813.A5 
Knee, C. R., \& Neighbors, C. (2002). Self-determination, perception of peer pressure, and drinking among college students. Journal of Applied Social Psychology, 32, 522-543. doi: 10.1111/j.1559-1816.2002.tb00228.x

LaBrie, J. W., Cail, J., Hummer, J. F., Lac, A. \& Neighbors, C. (2009). What men want: The role of reflective opposite-sex normative preferences in alcohol use among college women. Psychology of Addictive Behaviors, 23, 157-162. doi: $10.1037 / \mathrm{a} 0013993$

Larimer, M. E., \& Cronce, J. M. (2007). Identification, prevention, and treatment revisited: Individual-focused college drinking prevention strategies 1999-2006. Addictive Behaviors, 32, 2439-2468. doi: 10.1016/j.addbeh.2007.05.006

Larimer, M. E., Turner, A. P., Anderson, B. K., Fader, J. S., Kilmer, J. R., Palmer, R. S., \& Cronce, J. M. (2001). Evaluating a brief alcohol intervention with fraternities. Journal of Studies on Alcohol, 62(3), 370-380.

Lee, C. M., Geisner, I. M., Lewis, M. A., Neighbors, C., \& Larimer, M. E. (2007). Social motives and the interaction between descriptive and injunctive norms in college student drinking. Journal of Studies on Alcohol and Drugs, 68(5), 714-721.

Leffingwell, T. R., Neumann, C., Leedy, M. J., \& Babitzke, A. C. (2007). Defensively biased responding to risk information among alcohol-using college students. Addictive Behaviors, 32, 158-165. doi:10.1016/j.addbeh.2006.03.009

Mallett, K. A., Turrisi, R., Larimer, M. E., \& Mastroleo, N. R. (2009). Have I had one drink too many? Assessing gender differences in misperceptions of intoxication among college students. Journal of Studies on Alcohol and Drugs, 70(6), 964970. 
Marlatt, G. A., Baer, J. S., Kivlahan, D. R., Dimeff, L. A., Larimer, M. E., Quigley, L. A., Somers, J. M., \& Williams, E. (1998). Screening and brief intervention for high-risk college student drinkers: Results from a 2-year follow-up assessment. Journal of Consulting and Clinical Psychology, 66, 604-615. doi: 10.1037/0022006X.66.4.604

Murphy, J. G., Benson, T. A., Vuchinich, R. E., Deskins, M. M., Eakin, D., Flood, A. M., McDevitt-Murphy, M. E., \& Torrealday, O. (2004). A comparison of personalized feedback for college student drinkers delivered with and without a motivational interview. Journal of Studies on Alcohol, 65(2), 200-203.

Murphy, J. G., Duchnick, J. J., Vuchinich, R. E., Davison, J. W., Karg, R. S., Olson, A. M., Smith, A. F., \& Coffey, T. T. (2001). Relative efficacy of a brief motivational intervention for college student drinkers. Psychology of Addictive Behaviors, 15, 373-379. doi: 10.1037/0893-164X.15.4.373

Neighbors, C., Larimer, M. E., \& Lewis, M. A. (2004). Targeting misperceptions of descriptive drinking norms: Efficacy of a computer-delivered personalized normative feedback intervention. Journal of Consulting and Clinical Psychology, 72, 434-447. doi: 10.1037/0022-006X.72.3.434

Neighbors, C., Lewis, M. A., Bergstrom, R. L., \& Larimer, M. E. (2006). Being controlled by normative influences: Self-determination as a moderator of normative feedback alcohol intervention. Health Psychology, 25, 571-579. doi: $10.1037 / 0278-6133.25 .5 .571$

Perkins, H. W. (2002). Surveying the damage: A review of research on consequences of alcohol misuse in college populations. Journal of Studies on Alcohol, 14, 91-100. 
Pilling, V. K., \& Brannon, L. A. (2007). Assessing college students' attitudes toward responsible drinking messages to identify promising binge drinking intervention strategies. Health Communication, 22(3), 265-276.

Saitz, R., Palfai, T. P., Freedner, N., Winter, M. R., MacDonald, A., Lu, J., Ozonoff, A., Rosenbloom, D. L., \& Dejong, W. (2007). Screening and brief intervention online for college students: The iHealth study. Alcohol \& Alcoholism, 42, 28-36. doi: 10.1093/alcalc/ag1092

Sweeny, K., Melnyk, D., Miller, W., \& Shepperd, J. A. (2010). Information avoidance: Who, what, when, and why. Review of General Psychology, 13, 340-353. doi: $10.1037 / \mathrm{a} 0021288$

Testa, M., \& Parks, K. A. (1996). The role of women's alcohol consumption in sexual victimization. Aggression and Violent Behavior, 1, 217-234. doi: 10.1016/13591789(95)00017-8

Ullman, S. E., Karabatsos, G., \& Koss, M. P. (1999b). Alcohol and sexual assault in a national sample of college women. Journal of Interpersonal Violence, 14, 603625. doi: $10.1177 / 088626099014006003$

Vik, P. W., Carrello, P., Tate, S. R., \& Field, C. (2000). Progression of consequences among heavy-drinking college students. Psychology of Addictive Behaviors, 14, 91-101. doi: 10.1037/0893-164X.14.2.91

Walters, S. T., \& Neighbors, C. (2005). Feedback interventions for college alcohol misuse: What, why, and for whom? Addictive Behaviors, 30, 1168-1182. doi: 10.1016/j.addbeh.2004.12.005 
Walters, S. T., Vader, A. M., Harris, T. R., Field, C. A., \& Jouriles, E. N. (2009).

Dismantling motivational interviewing and feedback for college drinkers: A randomized clinical trial. Journal of Consulting and Clinical Psychology, 77, 64-

73. doi: $10.1037 / \mathrm{a} 0014472$

Weitzman, E. R. (2004). Poor mental health, depression, and associations with alcohol consumption, harm, and abuse in a national sample of young adults in college. Journal of Nervous and Mental Disease, 192, 269-277. doi:

10.1097/01.nmd.0000120885.17362.94

White, H. R., Mun, E. Y., \& Morgan, T. J. (2008). Do brief personalized feedback interventions work for mandated students or is it just getting caught that works? Psychology of Addictive Behaviors, 22, 107-116. doi: 10.1037/0893164X.22.1.107

White, H. R., Mun, E. Y., Pugh, L. \& Morgan, T. J. (2007). Long-term effects of brief substance use interventions for mandated college students: Sleeper effects of an in-person personal feedback intervention. Alcohol: Clinical and Experimental Research, 31, 1380-1391. doi: 10.1111/j.1530-0277.2007.00435.x 
APPENDIX A. Review of the Literature

\section{Problems and Consequences}

Heavy episodic alcohol consumption has been a persistent problem on American college campuses for at least the last three decades. Despite increased rates of alcoholrelated injuries and deaths (Hingson, Zha, \& Weitzman, 2009), the rate of binge drinking among college students has remained high, with more than one in three students engaging in binge drinking at least occasionally (Johnston, O’Malley, Bachman, \& Schulenberg, 2011). Almost half of student drinkers (48\%) cite 'drinking to get drunk' as a strong motive for alcohol consumption (Wechsler \& Nelson, 2008). According to the National Institute on Alcohol Abuse and Alcoholism (2004), high-risk drinking is defined as the consumption of at least five drinks for men and four drinks for women in roughly a twohour period. Such heavy drinking patterns have been associated with negative consequences not only for those that engage in such drinking but also for the people around them and the institutions with which they are associated (Perkins, 2002).

High-risk drinking can lead to both short-term and long-term consequences for college students, including financial, academic, interpersonal, physical, and legal problems. It has been estimated that the average college student spends $\$ 50$ each month on beer alone (Eigen, 1991). Those who drink heavily place themselves at increased risk for decreased physical health (e.g., upper respiratory infections) (Engs \& Aldo-Benson, 1995; Ham \& Hope, 2003) as well as more chronic conditions such as coronary heart and liver disease (Barbosa, Taylor, Godfrey, Rehm, Parrott, \& Drummond, 2010). They are 
likely to report poor mental health and emotional problems such as depression (Weitzman, 2004); and high percentages of heavy-drinking students report falling behind in class, forgetting where they went or what they did ("blacking out"), and engaging in unplanned sex (Vik et al., 2000). Higher rates of unplanned/unprotected sex with multiple or casual partners (Cooper, 2002; Perkins, 2002) in and of itself poses a risk in terms of sexually transmitted diseases (STDs) and unplanned pregnancy.

Heavy episodic drinking among college students also poses severe risks in terms of legal consequences, injuries, unintended fatalities, and suicide (Hingson et al., 2009; Perkins, 2002). Binge drinking has also been associated with increased rates of sexual assault (Testa \& Parks, 1996; Ullman et al., 1999b) and aggression leading to police intervention (Wechsler \& Nelson, 2008). It has been found that as high as 33 percent of high-risk drinkers report damaging or vandalizing others' property as a result of intoxication, and as many as 10 percent of men and three percent of women who drink heavily acknowledge that they have sexually taken advantage of someone within the last year (Perkins, 2002). In a recent report (Hingson et al., 2009), approximately one in three college students (28.9\%) between the ages of 18 and 24 reported driving under the influence of alcohol in the past year, and 10 percent reported being unintentionally injured due to drinking (e.g., traffic accidents, falls, drowning, burns, gunshot wounds, and suffocation). Moreover, it is estimated that alcohol contributes to the unintended death of over 5,000 young adults between the ages of 18 and 24 in the United States annually (Hingson et al., 2009).

While they impose extensive damage on themselves, college students who engage in risky drinking also inflict a number of negative consequences on others. Adverse 
aftermath of such behaviors includes property damage, vandalism, sexual/physical assault, harassment, public disturbance, and decreased quality of campus life (Ham \& Hope, 2003; Perkins, 2002; Marlatt, Larimer, Baer, \& Quigley, 1993). In 2005, approximately 12 percent of full-time college students reported being hit or assaulted by a peer who was drinking, and two percent were sexually assaulted or raped (Hingson et al., 2009). It is likely that intoxication, above and beyond one's personal level of aggression, contribute to this increase in assault, as research has found that greater male offender misperceptions of the amount of alcohol that a woman has had is associated with more severe sexual aggression (e.g., completed rape) (Ullman, Karabatsos, \& Koss, 1999a). Furthermore, that 30 percent of students who drive drunk (Hingson et al., 2009) place both themselves and others at risk for injury or even death. While such numbers are concerning, the impact of student drinking can also affect the more quotidian aspects of their peers' lives, such as interrupted studying or sleeping or having to take care of a drunken friend or roommate (Ham \& Hope, 2003; Perkins, 2002; Rhodes et al., 2009). Heavy drinking behaviors also affect the colleges and universities in which students are involved. Property damage in residence halls, public restrooms, and athletic arenas; decreased enrollment due to failed classes; impaired public image or relations due to negative alcohol-related incidents; and increased demands on personnel in terms of security assistance, administrative hearings, and disciplinary actions all have deleterious effects on the institutions with which heavy-drinking college students interact (Perkins, 2002). Moreover, excessive drinking creates preventable healthcare expenditure, incurring unnecessary costs to societies worldwide (Barbosa et al., 2010; Cortez-Pinto et 
al., 2010). It has been estimated that the consumption, abuse, and treatment of alcohol costs our society $\$ 86$ billion each year (Eigen, 1991).

Failing to truly understand and prevent these negative consequences places students at risk for compromising the quality of their future lives and careers, and in some cases forfeits one's future all together. Estimates from 1998 to 2005 suggest that anywhere from 300 to 470 college students die from alcohol-related, unintentional injuries each year (Hingson, Heeren, Winter, \& Wechsler, 2005). Students' decisions regarding alcohol consumption have important implications not only for student drinkers but for the families that grieve for them, the peers that cope with the second-hand effects of binge drinking (Wechsler \& Nelson, 2008), and the institutions that are forced to compensate for the consequences of their behaviors (Perkins, 2002).

\section{Effective Prevention and Intervention}

In response to such findings, colleges and universities have implemented a range of alcohol prevention and intervention programs. Of those employed, interventions involving personalized feedback have been some of the most promising to date (Carey, Scott-Sheldon et al., 2007; Larimer \& Cronce, 2007). Personalized feedback is currently a key component of many individualized alcohol interventions for college students, and it has been at least moderately effective in reducing alcohol consumption and related consequences, especially among high-risk drinkers (Carey, Scott-Sheldon et al., 2007; Larimer \& Cronce, 2007; Walters \& Neighbors, 2005). Stemming from motivational and social psychology (Walters \& Neighbors, 2005), personalized feedback interventions (PFIs) are intended to increase students' awareness of drinking habits and costs and to 
encourage students to thoughtfully consider their use of alcohol and related consequences in hopes that students who do so may alter their use of alcohol in the future.

Numerous investigations of PFIs have been reported in the literature. In a recent meta-analysis of controlled alcohol intervention studies for college drinkers (Carey, Scott-Sheldon et al., 2007), 51 of the 63 studies reviewed integrated either feedback or a normative comparison into the intervention. In an analysis of computer-based drinking interventions for the same population (Elliott, Carey, \& Bolles, 2008), nearly every intervention incorporated personalized feedback, either as the intervention itself or as an element of a multi-dimensional intervention. More importantly, in a review of the literature from 1999 to 2006 on individualized interventions for college student drinking (Larimer \& Cronce, 2007), over half of the 29 studies that manifested significant reductions in alcohol consumption and/or problems at follow-up employed feedback as a major element of the intervention. Thus, PFIs have been well studied and have evinced some of the most effective outcomes across studies (Carey, Scott-Sheldon et al., 2007; Elliott et al., 2008; Larimer \& Cronce, 2007).

To gain a more comprehensive understanding of the content domains included in personalized feedback profiles, we conducted a preliminary review of published studies incorporating personalized feedback as a major component of college student drinking interventions in the United States. To analyze the specific content of feedback profiles, authors were contacted and asked to supply a sample of the profile utilized in their studies. Twenty-nine authors responded and provided a sample. The content of each feedback profile was categorized into 10 primary content domains, each containing several secondary components (detailed below): (1) a personal drinking profile, (2) 
normative comparisons, (3) level of intoxication (BAC), (4) didactic information, (5) negative consequences of alcohol use, (6) practical consequences of alcohol consumption, such as calories consumed, (7) risk factors for alcohol-related problems, (8) expectancies of alcohol use, (9) strategies to moderate use and/or limit risk included in the profile, and (10) provision of local referral resources. A within-group Cohen's $d$ was also calculated for the change in drinking quantity for each condition for which means and standard deviations were provided.

PFIs appear to be effective across various modes of delivery, whether conveyed via the mail, a computer, or an individual interview. Written feedback interventions have been found to be as effective as in-person applications (Butler \& Correia, 2009; Carey, Carey, Maisto, \& Henson, 2006), computerized applications tend to have slightly smaller but still significant effects (Butler \& Correia, 2009; Doumas, Haustviet, \& Coll, 2010), and the use of a motivational interview may or may not add to the efficacy of the treatment (Juarez et al., 2006). The duration of effect, however, does seem to differ as a function of the intervention's mode of delivery.

In-person interventions. The efficacy of feedback discussed within the context of a BMI has been evidenced for up to two years (Baer, Marlatt, Kivlahan, Fromme, Larimer, \& Williams, 1992), with the largest within-group effect size evinced at six-week follow-up (Borsari \& Carey, 2000, $d=.81$ ). The efficacy of similar feedback within the context of a group BMI session has been supported for up to a year (Larimer et al., 2001, $d=.28$ ), again with the largest effect at six weeks (Walters, Bennett, \& Miller, 2000, $d=$ .60). An individual BMI without a feedback component has been found to be effective for up to six months (Walters et al., 2009, $d=.28$ ), with two-month effect sizes (Juarez et al., 
2006, $d=.80$ ) equal to the six-week effects of feedback-enhanced BMI (Borsari \& Carey, 2000). However, the long-term efficacy of BMI alone in reducing drinking quantity has not been confirmed past six months, thus conclusions regarding its long-term efficacy are unwarranted at this point.

Mailed interventions. Effects for mailed PFIs have been demonstrated only up to two months (Juarez et al., 2006, $d=1.09$ ), with longer-term studies finding negative effect sizes (Collins, Carey, \& Sliwinski, 2002, six-month $d=-0.61$; Larimer et al., 2007, 12-month $d=-0.03$ ). However, Larimer and colleagues (2007) found that the intervention significantly reduced the amount that fraternity members increase in drinking from freshmen to sophomore years in college; and in the short term, mailed feedback interventions appear to have some of the most salient effects of all feedback applications. Specifically, two of the largest within-group effect sizes were found in studies utilizing mailed feedback [Juarez et al., 2006, two-month $d=1.09$ and Walters et al., 2000, sixweek effect size $(E S)=1.01]$. Moreover, the use of mailed personalized feedback in conjunction with an in-person BMI appears to have a synergistic effect, evincing effects for up to two years (Marlatt et al., 1998, $d=.46$ ). In fact, the study yielding the largest effect size of all interventions utilized this combination of applications (Juarez et al., $2006, d=1.27)$. Thus, an in-person interview seems to increase the duration of the relatively potent effects of mailed feedback alone.

Computerized interventions. Effects of computerized feedback interventions have been evinced for up to six months (Neighbors, Larimer, \& Lewis, 2004, $d=.28$ ), with the largest effect reported at three months (Doumas et al., 2010, $d=.57$ ). Again, the only long-term study of computerized feedback for which an effect size could be calculated 
found negative effect sizes (White, Mun, Pugh, \& Morgan, 2007, 15-month $d=-0.14$ ).

One study incorporating computerized feedback into a BMI session was also effective at a six month follow-up (Murphy et al., 2004). Murphy and colleagues (2004) report that the within-group effect size across quantity, frequency, and heavy drinking measures was $d=.48$ for those in the computerized PFI plus BMI group and $d=.42$ for those viewing a computerized PFI alone. As such, there does not seem to be much evidence that an inperson interview enhances the effects of the computerized PFI. However, since no studies have examined either application past six months, further research is needed to examine the maintenance of such effects over time.

\section{Limitations of Previous Research}

\section{Variability of PFIs}

Although effects are promising, PFIs vary widely across studies in terms of both research design and content. Though the majority of studies utilize an indicated prevention strategy to target high-risk college student drinkers, studies differ in terms of 'high risk drinking' criteria, methodology, comparison group, follow-up period, and feedback content. While some studies test the efficacy of the feedback profile alone, an equivalent number of studies utilize feedback to supplement an individual or group meeting. Several studies also incorporated both formats in an attempt to disentangle the effects of the individual session from those of the feedback alone. Follow-up assessments have ranged from one month to two years. Likewise, the content of different feedback profiles varies in both over-arching content domains and the specific content components of which the domains are comprised. 
Personalized drinking profile. All feedback profiles included a personal drinking summary of, at least, the typical quantity of alcohol that the student self-reported drinking. Some profiles also included the student's typical drinking frequency, as well as peak quantities and frequencies, and one profile summarized the students' frequency and quantity of alcohol use during high school. The majority of profiles also included information regarding the student's peak and/or typical level of intoxication (blood alcohol concentration, or BAC). Some also included details regarding BAC on a specific night (e.g., the night of an incident that incited a referral), and some educated students on the amount of time required for their BAC to return to zero.

Since the earliest studies of personalized feedback (Miller, Sovereign, \& Krege, 1988), feedback profiles regularly have included a list of negative consequences that students report experiencing due to drinking. Not surprisingly, then, over half of the studies reviewed included a list of negative consequences attributable to alcohol use. In addition to the more defining consequences of alcohol use, Walters et al. (2000) began the trend of incorporating practical costs such as money into PFIs for at-risk college drinkers. Larimer et al. (2001) expanded these costs to include variables such as calories consumed. Collectively, almost half the feedback profiles incorporated some kind of practical cost into their feedback profiles. Such costs included calories consumed, with or without a caloric equivalent (e.g., cheeseburgers) and portrayal of their concern about weight gain; hours of exercise required to burn off those calories; financial costs, depicted with or without a monetary equivalent (e.g., flat-screen TV's); and time spent away from other valued activities. Though few studies have examined the benefit of incorporating this specific information into brief interventions for college students, Saitz 
and colleagues (2007) found that information regarding peak BAC and effects of BAC levels, negative consequences, and practical consequences did not add to the effectiveness of a more basic profile including only normative feedback and didactic information. However, this finding may reflect students' inability to remember a large amount of detailed information, rather than a preference for a particular set of components over another. Thus, it may be that students simply prefer a more limited amount of feedback information.

Normative comparisons. Along with the personal drinking summary, the one feedback component incorporated in all PFIs was a descriptive normative comparison. The use of normative comparisons comes largely from social norms theory (Perkins \& Berkowitz, 1986). Though perceptions of peer behaviors and beliefs can influence student alcohol use both directly (i.e., making alcohol available) and indirectly (modeling and normalizing drinking behavior) (Borsari \& Carey, 2001), social norms theory focuses on indirect peer influence. It contends that alcohol use, as all health behaviors, is influenced by an individual's misperceptions of the attitudes and behaviors of their peers. These perceptions have been divided into the motivational elements of what is (descriptive norms) and what ought to be (injunctive norms) (Cialdini, Reno, \& Kallgren, 1990). In this case, then, descriptive norms refer to actual drinking behavior (e.g., a student's belief that 80 percent of college students drink), while injunctive norms refer to approval or disapproval of drinking behaviors (e.g., a student's belief that 80 percent of college students think drinking is normal, right, or good).

Self-regulation theory (Agostinelli, Brown, \& Miller, 1995) adds to the conceptualization of social norms by suggesting that college students will conform their 
own behavior to their perceptions of that behavior among their peers. In terms of college drinking, this implies that misperceptions of typical drinking patterns contribute to one's own misuse of alcohol. Because they overestimate the prevalence of drinking in their social group, heavy drinkers view their drinking as normal rather than excessive. Until they recognize the discrepancy between their own drinking pattern and that of their peers, however, they will not self-correct this behavior. Thus, normative feedback illuminates this discrepancy in hopes that awareness of it will facilitate the drinker's self-change (Agostinelli et al., 1995). In line with this theory, research has found that college students consistently overestimate the amount of alcohol their peers consume (Perkins, Haines, \& Rice, 2005), and these overestimations are positively correlated with students' actual drinking behaviors (Martens, Page, Mowry, Damann, Taylor, \& Cimini, 2006). Thus, personalized normative feedback interventions are designed to correct normative misperceptions in order to moderate heavy drinking.

A handful of studies have demonstrated that descriptive normative comparisons alone can indeed reduce heavy drinking among college students. Though referents changed across studies, research has shown that participants in a personalized normative feedback condition significantly decreased their drinking as compared to control participants at one-, two-, and three-month follow-ups and that changes in perceived norms mediated this effect (Lewis \& Neighbors, 2007; Neighbors et al., 2004; Neighbors, Lewis, Bergstrom, \& Larimer, 2006). Research utilizing additional feedback components has also found that personalized normative feedback is effective in reducing normative perceptions and alcohol consumption (Barnett, Murphy, Colby, \& Monti, 2007; Borsari 
\& Carey, 2000; Walters, 2000; Walters et al., 2000). Such research suggests that students have interest in the drinking patterns of their peers.

Though prior research has focused on normative comparisons of drinking frequency and quantity (Lewis, Neighbors, Geisner, Lee, Kilmer, \& Atkins, 2010), several studies have strayed from this tradition, including normative information regarding frequency of binge drinking, frequency of moderate drinking (e.g., two drinks or less per week), prevalence of abstinence on campus, frequency of other illicit drug use, and number of alcohol-related consequences (Borsari \& Carey, 2005; Collins et al., 2002; Hustad, Barnett, Borsari, \& Jackson, 2009; Walters, Vader, \& Harris, 2007; White, Mun, \& Morgan, 2008). Because high-risk drinkers also overestimate the number of alcoholrelated consequences that the typical college student endures (Lee, Geisner, Patrick, \& Neighbors, 2010), this particular normative comparison may be more interesting to highrisk drinkers.

Interestingly, none of the studies reviewed employed injunctive norms. However, recent research suggests that 'reflective' normative feedback, or the perceived preference of the opposite sex for one's alcohol use, may be effective in eliciting behavior change specifically for female college students (LaBrie, Cail, Hummer, Lac, \& Neighbors, 2009). LaBrie and colleagues (2009) found that female college students overestimate the amount of alcohol that their male peers want a typical woman to drink as well as the amount that men want their friends, the girls they date, and their sexual partners to drink. More importantly, women's misperceptions of their male peers' preferences were more strongly associated with women's actual drinking behavior than were demographic factors or their perceptions of other women's alcohol consumption. Such findings suggest 
that the use of this specific injunctive norm may be effective especially for female college drinkers.

Though all feedback interventions included a descriptive normative comparison, the profiles varied widely in terms of the normative referent used. While some studies compared students' drinking to other college students on campus, some compared their drinking to the normative drinking behavior of other students in the United States; some, to other students their age; and some, to those in their specific class. Likewise, several studies utilized a sex-specific referent, comparing students' drinking to other men/women on campus, across the nation, his/her age, or within his/her class. However, no studies utilized normative comparisons to members of one's ethnicity, which has been identified as a potentially valuable source of comparison drinkers (Lewis \& Neighbors, 2007), and only about half of profiles indicated the source of the normative comparison.

Conceptually, several psychological perspectives (Social Comparison Theory, Social Identity Theory, Social Impact Theory, and Social Learning Theory) suggest that the choice of normative referent is critical in eliciting behavior change (Walters \& Neighbors, 2005). Specifically, these theories propose that individuals attend better to information regarding people with whom they believe they are more similar. For example, fraternity members may be more interested in their rank among other fraternity members because the comparison seems more relevant to them; however, the discrepancy between actual and perceived drinking may be less effective in this case due to the typically elevated drinking patterns within this group (Walters \& Neighbors, 2005). Similarly, researchers found that the referent of the 'typical college student' may be less effective for women, who were found to perceive the typical student as male (Lewis \& 
Neighbors, 2006). Such research suggests that female college students may benefit more from comparison to other women because the female drinking norm is lower (Lewis \& Neighbors, 2007; Walters \& Neighbors, 2005). For these reasons, the balance between the proximity of the referent and the potential discrepancy between actual and perceived norms is crucially important in choosing the most effective comparison (Walters and Neighbors, 2005).

Didactic information. Based on the premise that access to accurate information will improve student functioning and facilitate safer use of alcohol, education regarding the psychological and physiological effects, influential factors, and risks associated with drinking has been a relatively stable first step in the prevention of alcohol abuse (Meier, 1988). Because a range of materials and information is available, however, it is also the feedback component in which studies varied most. Didactic information included one or more pieces of educational information not directly related to interpretation of the feedback. The specific feedback components included typical effects of different BAC levels (e.g., 0.02-0.04 relaxation, 0.05 impaired judgment); clarification of chemical effects versus cultural expectancies of alcohol (i.e., placebo effects); biphasic responses to alcohol; alcohol interactions with other chemicals, such as medications, caffeine and energy drinks, and other drugs, as well as the way it affects one's ability to burn calories, build muscles, and heal; how to calculate BAC and factors that do or do not affect one's BAC level (drinking on a full stomach versus having a bloody Mary the next morning); statistics regarding one's increased risk in general (leading cause of death, etc.); definitions of tolerance (lack of a built-in warning system) and withdrawal (i.e., indicative symptoms); and college student alcohol consumption as a money-making 
business. Some studies also provided opportunities for further education by providing hyperlinks with additional information on certain topics.

Over 80 percent of studies incorporated some kind of didactic information into their feedback profiles. Though not always portrayed as an educational component of personalized feedback, the majority of studies also evaluated students' personal risk factors for future alcohol-related problems. Feedback components included tolerance level, a positive family history of alcohol-related problems, past consequences (usually an AUDIT score), binge drinking and/or drinking game participation, other drug use, and/or psychological symptomology. In summarizing such personal risk factors, profiles often also provided educational information regarding the implications of such risks (e.g., increased risk associated with binge drinking and/or participation in drinking games as well as implications of a positive family history for alcohol problems).

Overall, didactics-based programs appear to be less effective than feedback-based approaches. The largest within-group effect size for an educational program was found at three months (Borsari \& Carey, 2005, $d_{\text {in-person AE }}=.31$ ), as compared to the largest threemonth effect sizes of in-person PFI-BMI (Murphy et al., 2001, $d=.47$ ) and computerized PFI interventions (Doumas et al., 2010, $d=.57$ ). Likewise, the only studies examining the long-term effects of educational programs found negative effect sizes (Larimer et al., 2001, one-year $d_{\mathrm{AE} \text { group }}=-0.14$, and Barnett et al., 2007, one-year $d_{\text {computerized } \mathrm{AE}}=-0.16$ ). One explanation for this may be that students respond more favorably to personally relevant information. In support of this idea, research has found that students find personalized messages (i.e., my drinking, BAC levels, and risks) more interesting than public service announcements regarding the anonymous drinking behavior of their peers 
(Pilling \& Brannon, 2007). Thus, the personalization of educational information may be critical. However, because such a large percentage of studies incorporated some kind of didactic information into their feedback profiles, the importance of such information should not be disregarded.

Behavioral components. The widely ineffective use of purely educational programs on college campuses led researchers to begin employing behavioral strategies within their prevention programs. Commonly based on social learning principles, the goals of such techniques were often self-management (e.g., pacing oneself and mixing weaker drinks), self-monitoring (keeping track of one's BAC), and self-assertion (declining to participate in drinking games) (Garvin, Alcorn, \& Faulkner, 1990). Because heavy drinking seems to be a pervasive part of the environment on many college campuses, researchers sought a more practical way of preventing students from the consequences associated with such high-risk behaviors (Martens, Taylor, Damann, Page, Mowry, \& Cimini, 2004). Behavioral strategies to limit alcohol-related risk can be taught and focus specifically on consequences rather than alcohol consumption, thus they seemed to be the most practical way of helping students protect themselves in such environments (Martens et al., 2004). Indeed, research has found that students who reported use of fewer strategies were at least twice as likely to experience negative alcohol-related consequences as those who reported more frequent use of protective strategies (Martens et al., 2004). Interestingly, though several of the studies reviewed provided students with a list of strategies to moderate use and limit alcohol-related risk, only two studies incorporated a practice component that would, theoretically, improve students' self-efficacy to utilize such strategies. 
Cognitive components. According to social learning theory, behavioral changes are mediated by the cognitive mechanisms of outcome expectancy and efficacy expectation (Bandura et al., 1977). Alcohol outcome expectancies refer to the individual's beliefs about the consequences, either positive or negative, of alcohol use (Noar, LaForge, Maddock, \& Wood,1993). Self-efficacy refers to the belief that one can successfully perform the behavior required for the outcome (Bandura et al., 1977). Because alcohol expectancies are conceived as long-term memories that can be developed in childhood, changing these expectancies can be difficult (Darkes \& Goldman, 1993). Cognitive-behavioral techniques, then, often work simultaneously to challenge these maladaptive expectations and to build one's self-efficacy for change.

The cognitive components of drinking prevention seem to be relatively underrepresented within the PFI literature. Only about one in four studies assessed students' expectations of their alcohol use (e.g., increased sociability and reduced tension), at least two of which did not include an expectancy challenge exercise. Expectancies have been implicated in actual drinking behavior, such that positive expectancies should be associated with higher levels of alcohol consumption and negative expectancies should be associated with lower levels of drinking (Noar et al., 1993). Findings within the literature, however, have been mixed. Specifically, positive expectancies have been positively associated and unassociated with drinking behavior, while negative expectancies have been negatively-, positively-, and un-related to drinking (Noar et al., 1993). It has been suggested that, because the positive effects of alcohol (feeling relaxed) are relatively immediate but the negative effects are often delayed 
(hangovers, poor health), positive expectancies may have a larger impact on drinking than negative expectancies (Noar et al., 1993).

Likewise, based on the premise that consideration of a situation in which the pros of a decision out-weight the cons will lead an individual to choose the behavior eliciting more benefits, at least a fourth of studies incorporated either a pro-con list or decisional balance to clarify students' perceptions of alcohol use. Similar to studies of expectancy challenges, however, the only study comparing interventions with and without a decisional balance found no support for the additive benefit of this component (Carey et al., 2006). Previous studies (Collins \& Carey, 2005) have also failed to find support either in-person or written decisional balances as a stand-alone drinking intervention for college students.

Accounting for Individual Differences

Similar to the variations of content among PFIs, college students seem to vary in their responses to personalized feedback (Carey, Henson, Carey, \& Maisto, 2007). A number of moderators have been tested to determine individuals for whom feedback may be most effective, the most frequently evaluated being sex. Examination of several predicted moderators suggests that personalized feedback seems effective despite a number of individual differences. Changes in drinking have been similar irrespective of race/ethnicity, year in school, family history of alcohol problems, history of conduct problems, site of recruitment, type of student residence, motivation to change, and desire to avoid risks (Borsari \& Carey, 2005; Chiauzzi, Green, Lord, Thum, \& Goldstein, 2005; Larimer et al., 2001; Marlatt et al., 1998; Walters et al., 2009; White et al., 2008) as well as across psychological variables such as stress and symptomatology (Baer et al., 1992). 
Also, for mandated referrals, Borsari and Carey (2005) found no evidence that days between student infraction and receipt of intervention affected the efficacy of the intervention. However, a handful of variables have been found to differentiate between students who do and do not respond well to personalized feedback, two of these being sex and susceptibility to peer pressure.

Sex differences. Several studies have found changes in drinking related to sex, often regardless of treatment condition. The trends, however, are inconsistent. Collins et al. (2002), for example, found that men decreased in drinks per week during the six weeks postintervention while women did not. Murphy et al. (2004) and Saitz et al. (2007) found the opposite, that high-risk women but not men decreased in weekly drinking at six-month and one-month follow-ups, respectively. Juarez and colleagues (2006) also found that women but not men who received feedback reported reductions in dependency symptoms as compared to those in MI only and control conditions. Though they found no difference in drinking quantity, White et al. (2007) also reported that, four months after baseline, women demonstrated a greater reduction than men in alcohol-related problems. Interestingly, women have been found to respond more favorably to responsible drinking messages than men (Pilling \& Brannon, 2007). This may be due to the finding that women seem to overestimate normative comparisons (Borsari \& Carey, 2003) and underestimate their own levels of intoxication during moderate episodes of drinking (Mallett, Turrisi, Larimer, \& Mastroleo, 2009) to a greater extent than men. Thus, women may rate feedback, and specifically normative feedback, as interesting and motivating to a greater extent than men. 
Social reasons for drinking. Susceptibility to peer pressure also seems to differentiate between those students who benefit most from PFIs. At three (but not six) months, Neighbors et al. (2004) found that personalized feedback was somewhat more effective for participants who drank for social reasons, suggesting that students who drink for social reasons may be more responsive to social comparisons. Lee, Geisner, Lewis, Neighbors, \& Larimer (2007) also found that students who drink for social reasons are more strongly driven by their descriptive and injunctive perceptions of close friends' drinking (i.e., they believe their friends both drink a lot and approve of risky drinking) than those who report low social motives for drinking. Controlled orientation, or the tendency to perceive environmental pressure and lack of true control over one's choices, has also been found to moderate the effect of PFIs specifically on alcohol-related consequences (Neighbors et al., 2006). In an earlier study by Knee and Neighbors (2002), the relationship between such extrinsic motives for drinking and actual drinking was mediated by perceived peer pressure from friends. Thus, it is plausible that social drinkers and students who are more sensitive to peer pressure may find normative feedback information more compelling than those who are not.

\section{Student Preferences}

A substantial amount of data regarding the negative effects of high-risk drinking and the methods of preventing it is available in the literature. Despite consistent efforts to reduce binge drinking among college students, the prevalence of heavy drinking in this population has remained stable over the last 15 to 20 years (Hingson et al., 2009). The stability of this drinking pattern may be due in part to use of content domains and components that college students, and specifically high risk drinkers, find personally 
irrelevant or unimportant. Due to inconsistencies across studies, we have been unable to make strong inferences regarding which feedback components are most effective and which are most salient to college students. Research has found that college student drinkers do not tend to view college drinking as an important problem, they are skeptical of the scientific merit of alcohol risk information, and they generally do not view themselves as being in personal risk of alcohol-related problems (Leffingwell, Neumann, Leedy, \& Babitzke, 2007). Thus, interventions designed to provide students with feedback information that they want to know may disarm such defensive responding in high-risk drinkers.

Students historically have reported higher levels of satisfaction and willingness to recommend PFIs to a friend (Borsari \& Carey, 2000; Borsari \& Carey, 2005) than levels of personal relevance (Borsari \& Carey, 2005; Murphy et al., 2001; Collins et al., 2002). Specifically, when satisfaction ratings were divided by the highest possible rating (e.g., a mean score of 3.4 on a 4-point scale would be equivalent to a mean rating of 85 while a score of 7.3 on a 10-point scale would yield a mean rating of 73), studies have reported mean satisfaction ratings of 88 (Borsari \& Carey, 2000). White et al. (2007) also found that $83.8 \%$ of students were either satisfied or very satisfied with their in-person PFI and $78.9 \%$ of students were equally satisfied with the computerized PFI. On ratings of personal relevance and effectiveness, however, studies have yielded ratings of 64 for a mailed PFI (Collins et al., 2002) and 71 to approximately 75 for in-person PFIs (Borsari \& Carey, 2005; Murphy et al., 2001).

Though all interventions were rated at moderately to high levels, there is some evidence that feedback interventions that are rated as more favorable for a sub-group of 
students will also be more effective for that group. Specifically, Murphy et al. (2001) found that an in-person PFI was rated as more personally relevant, interesting, and effective by heavier-drinking college students than by more moderate drinkers. At threemonth follow-up, students who received the PFI and reported a baseline of at least either 25 drinks per week or three heavy drinking nights per week demonstrated greater reductions in drinking than those in education or control conditions. Though participants in the education and control conditions improved at a slower rate, reaching equivalent reductions in drinking by nine months, the sharp decrease in drinking demonstrated by those in the PFI condition is arguably more urgent and therefore important for those students who put themselves at high risk for alcohol-related problems.

Because each of the PFI studies that provided student evaluations of feedback incorporated different content domains and follow-up periods, such ratings lend us no additional knowledge regarding which domains are more relevant to college students. However, when asked specifically which components of the intervention were least or most helpful, students have reported that the BAC calculations, handouts/feedback profile, and interaction with the counselor were most helpful (Marlatt et al., 1998; White et al., 2007) and that the paperwork and personally irrelevant or already familiar information was least helpful (Marlatt et al., 1998; White et al., 2007). Because neither of these studies included the full range of content domains, however, the literature warrants additional research regarding students' attitudes toward personalized feedback.

PFIs have been one of the most widely studied, empirically supported, and commonly implemented strategies for drinking prevention and intervention on college campuses (Carey, Scott-Sheldon et al., 2007; Larimer \& Cronce, 2007; Hingson, 2010). 
Yet the content of feedback interventions varies considerably across studies. Such inconsistencies are due in part to a general lack of knowledge regarding which intervention components work best for whom. Though previous research has attempted to elicit this information by experimentally dismantling interventions, such time-intensive methods are inefficient in accounting for such wide variations within the literature. No prior research has evaluated the rated effectiveness of intervention content domains as reported by college students themselves. Thus, research on student preferences for feedback may be the next step in refining PFIs for college student drinkers.

\section{The Present Study}

The goal of the current study is to assess college students' attitudes and preferences for PFI content domains and components in order to identify those messages that most effectively reduce problematic alcohol consumption among high-risk college student drinkers. The central tenet of the project is that, while students will demonstrate individual differences in preferences for domains, there are certain content domains that the majority of students will find either effective or irrelevant. The project aims to improve the quality of PFIs for heavy-drinking college students by identifying and comparing these preferences among groups of students. Based on prior research, the present study will test the hypotheses that:

1) Students will vary in preferences for different feedback components.

a. Students will be most interested in descriptive normative comparisons.

2) Patterns of preferences for women and men will differ.

3) Patterns of preferences for heavy drinkers and abstinent or light drinkers will differ. 
a. Heavy drinkers will be more interested in descriptive normative feedback than will abstinent or light drinkers.

4) The pattern of preferences for socially-motivated drinkers will differ from that of those who drink for other reasons.

a. Socially-motivated drinkers will be more interested in descriptive and injunctive normative feedback than those who drink for other reasons. 
APPENDIX B. Tables \& Figures

Table 1

Results of principal component analyses

\begin{tabular}{|c|c|c|c|c|}
\hline & $\begin{array}{l}\text { Rotated Factor } \\
1 \text { Loadings }\end{array}$ & $\begin{array}{l}\text { Rotated Factor } \\
2 \text { Loading }\end{array}$ & $\begin{array}{c}\text { Cumulative \% } \\
\text { Variance Explained }\end{array}$ & $\begin{array}{c}\text { Cronbach's } \\
\alpha\end{array}$ \\
\hline \multicolumn{5}{|c|}{ Drinking Profile } \\
\hline New & .716 & -.036 & & \multirow{6}{*}{.825} \\
\hline Interest & .806 & -.168 & & \\
\hline Relevance & 611 & -.470 & & \\
\hline Motivation & .837 & .217 & & \\
\hline Change & .844 & .235 & 49.39 & \\
\hline Skepticism & .113 & .854 & 67.40 & \\
\hline \multicolumn{5}{|c|}{ Descriptive Norm } \\
\hline New & .755 & .191 & & \multirow{6}{*}{.883} \\
\hline Interest & .828 & .000 & & \\
\hline Relevance & .782 & -.064 & & \\
\hline Motivation & .877 & -.045 & & \\
\hline Change & .861 & -.065 & 56.29 & \\
\hline Skepticism & -.010 & .987 & 73.32 & \\
\hline \multicolumn{5}{|c|}{ Percentile Ranking } \\
\hline New & .754 & -.042 & & \multirow{6}{*}{.882} \\
\hline Interest & .879 & -.064 & & \\
\hline Relevance & .803 & -.109 & & \\
\hline Motivation & .851 & .120 & & \\
\hline Change & .845 & .113 & 57.08 & \\
\hline Skepticism & .000 & .982 & 73.90 & \\
\hline \multicolumn{5}{|c|}{ Injunctive Norm } \\
\hline New & .731 & .257 & & \multirow{6}{*}{.880} \\
\hline Interest & .844 & -.004 & & \\
\hline Relevance & .809 & -.065 & & \\
\hline Motivation & 881 & -.016 & & \\
\hline Change & .870 & -.044 & 57.26 & \\
\hline Skepticism & -.004 & .983 & 74.54 & \\
\hline
\end{tabular}




\begin{tabular}{|c|c|c|c|c|}
\hline & $\begin{array}{c}\text { Rotated Factor } \\
1 \text { Loadings }\end{array}$ & $\begin{array}{l}\text { Rotated Factor } \\
\text { 2 Loading }\end{array}$ & $\begin{array}{c}\text { Cumulative \% } \\
\text { Variance Explained }\end{array}$ & $\begin{array}{c}\text { Cronbach's } \\
\alpha\end{array}$ \\
\hline \multicolumn{5}{|c|}{ Reflective Norm } \\
\hline New & .719 & .122 & & \\
\hline Interest & .865 & -.088 & & \\
\hline Relevance & .876 & -.054 & & \\
\hline Motivation & .879 & -.079 & & \\
\hline Change & .882 & -.096 & 60.12 & .897 \\
\hline Skepticism & -.043 & .990 & 76.80 & \\
\hline \multicolumn{5}{|l|}{$B A C$} \\
\hline New & .780 & .012 & & \\
\hline Interest & .867 & -.106 & & \\
\hline Relevance & .835 & -.094 & & \\
\hline Motivation & .870 & -.013 & & \\
\hline Change & .865 & -.018 & 59.42 & .898 \\
\hline Skepticism & -.048 & .997 & 76.32 & \\
\hline \multicolumn{5}{|c|}{ Didactic Information } \\
\hline New & .695 & .443 & & \\
\hline Interest & .866 & .076 & & \\
\hline Relevance & .834 & -.062 & & \\
\hline Motivation & .903 & .122 & & \\
\hline Change & .891 & .159 & 61.53 & .899 \\
\hline Skepticism & .044 & .969 & 78.75 & \\
\hline \multicolumn{5}{|l|}{ Strategies } \\
\hline New & .765 & .301 & & \\
\hline Interest & .894 & -.015 & & \\
\hline Relevance & .842 & -.162 & & \\
\hline Motivation & .879 & .159 & & \\
\hline Change & .893 & .116 & 62.02 & .906 \\
\hline Skepticism & .053 & .973 & 79.52 & \\
\hline \multicolumn{5}{|l|}{ Risk Factors } \\
\hline New & .840 & .067 & & \\
\hline Interest & .901 & -.031 & & \\
\hline Relevance & .842 & -.089 & & \\
\hline Motivation & .933 & -.038 & & \\
\hline Change & .913 & -.057 & 65.65 & .930 \\
\hline Skepticism & -.032 & .997 & 82.34 & \\
\hline \multicolumn{5}{|l|}{ Consequences } \\
\hline New & .738 & .338 & & \\
\hline Interest & .890 & .118 & & \\
\hline Relevance & .844 & -.069 & & \\
\hline Motivation & .918 & -.019 & & \\
\hline Change & .912 & -.006 & 62.59 & .913 \\
\hline Skepticism & .015 & .974 & 80.09 & \\
\hline
\end{tabular}




\begin{tabular}{|c|c|c|c|c|}
\hline & $\begin{array}{l}\text { Rotated Factor } \\
1 \text { Loadings }\end{array}$ & $\begin{array}{l}\text { Rotated Factor } \\
2 \text { Loading }\end{array}$ & $\begin{array}{c}\text { Cumulative \% } \\
\text { Variance Explained }\end{array}$ & $\begin{array}{c}\text { Cronbach's } \\
\alpha\end{array}$ \\
\hline \multicolumn{5}{|c|}{ Practical Costs } \\
\hline New & .833 & -.020 & & \\
\hline Interest & .890 & -.155 & & \\
\hline Relevance & .827 & -.048 & & \\
\hline Motivation & .892 & -.085 & & \\
\hline Change & .866 & -.060 & 62.03 & .915 \\
\hline Skepticism & -.080 & .996 & 79.19 & \\
\hline \multicolumn{5}{|c|}{ Cognitive Functioning } \\
\hline New & .772 & .114 & & \\
\hline Interest & .898 & -.123 & & \\
\hline Relevance & .847 & -.032 & & \\
\hline Motivation & .899 & -.102 & & \\
\hline Change & .894 & -.084 & 62.61 & .911 \\
\hline Skepticism & -.048 & .991 & 79.33 & \\
\hline \multicolumn{5}{|c|}{ Liver Functioning } \\
\hline New & .768 & .105 & & \\
\hline Interest & .899 & -.052 & & \\
\hline Relevance & .880 & -.106 & & \\
\hline Motivation & .892 & -.085 & & \\
\hline Change & .880 & -.082 & 62.41 & .914 \\
\hline Skepticism & -.047 & .992 & 79.47 & \\
\hline \multicolumn{5}{|l|}{ Genetic Risk } \\
\hline New & .761 & -.024 & & \\
\hline Interest & .902 & -.090 & & \\
\hline Relevance & .832 & -.039 & & \\
\hline Motivation & .863 & -.073 & & \\
\hline Change & .882 & -.067 & 60.20 & .904 \\
\hline Skepticism & -.067 & .997 & 77.11 & \\
\hline
\end{tabular}


Table 2

Differences in Affinity Ratings between High-Risk and Low-Risk Drinkers

\begin{tabular}{|c|c|c|c|c|c|c|c|}
\hline \multirow[b]{2}{*}{ Feedback Component } & \multicolumn{2}{|c|}{$\begin{array}{c}\text { Total Sample } \\
(N=397)\end{array}$} & \multicolumn{2}{|c|}{$\begin{array}{l}\text { High-Risk Drinkers } \\
\qquad(n=228)\end{array}$} & \multicolumn{2}{|c|}{$\begin{array}{c}\text { Low-Risk Drinkers } \\
(n=169)\end{array}$} & \multirow[b]{2}{*}{$t(395)$} \\
\hline & $M$ & $S D$ & $M$ & $S D$ & $M$ & $S D$ & \\
\hline Practical Costs & 2.73 & 2.32 & 2.55 & 2.31 & 2.98 & 2.32 & 1.82 \\
\hline Genetic Risk & 2.66 & 2.26 & 2.42 & 2.26 & 2.99 & 2.24 & $2.49 * *$ \\
\hline Liver Functioning & 2.64 & 2.22 & 2.34 & 2.25 & 3.04 & 2.13 & $3.12 * *$ \\
\hline $\mathrm{BAC}$ & 2.37 & 2.30 & 2.06 & 2.31 & 2.79 & 2.21 & $3.17 * *$ \\
\hline Risk Factors & 2.22 & 2.51 & 1.82 & 2.57 & 2.75 & 2.33 & $3.72 * * *$ \\
\hline $\begin{array}{l}\text { Cognitive } \\
\text { Functioning }\end{array}$ & 2.10 & 2.48 & 1.73 & 2.53 & 2.60 & 2.32 & $3.54 * * *$ \\
\hline Descriptive Norm & 2.02 & 2.44 & 1.57 & 2.45 & 2.62 & 2.30 & $4.39 * * *$ \\
\hline Consequences & 1.74 & 2.62 & 1.51 & 2.63 & 2.05 & 2.59 & $2.05 *$ \\
\hline Percentile Rank & 1.91 & 2.44 & 1.51 & 2.46 & 2.45 & 2.31 & $3.87 * * *$ \\
\hline Reflective Norm & 1.57 & 2.52 & 1.18 & 2.52 & 2.10 & 2.43 & $3.66 * * *$ \\
\hline Profile & .91 & 2.47 & 0.58 & 2.44 & 1.34 & 2.44 & $3.07 * *$ \\
\hline Injunctive Norm & .33 & .62 & 0.22 & .63 & .48 & .57 & $4.31 * * *$ \\
\hline Didactic Information & .57 & 2.78 & 0.13 & 2.75 & 1.17 & 2.72 & $3.77 * * *$ \\
\hline Strategies & .53 & 2.82 & 0.11 & 2.80 & 1.09 & 2.76 & $3.44 * * *$ \\
\hline Overall Affinity & 1.74 & .83 & 1.48 & 1.87 & 2.30 & 1.85 & $4.38 * * *$ \\
\hline
\end{tabular}

Note. Scores ranged from -5 to 5 , with higher scores indicating stronger affinity. ${ }^{*} p<.05$, $* * p<$ $.01, * * * p<.001$ 
Table 3

Pairwise Comparisons of Affinity Ratings for High-Risk Drinkers

\begin{tabular}{|c|c|c|c|c|c|c|c|c|c|c|c|c|c|c|c|}
\hline \multirow[b]{2}{*}{ Feedback Component } & \multicolumn{15}{|c|}{$\begin{array}{l}\text { High-Risk Drinkers } \\
\quad(n=228)\end{array}$} \\
\hline & Mean (SD) & 1. & 2. & 3. & 4. & 5. & 6. & 7. & 8. & 9. & 10. & 11. & 12. & 13. & 14. \\
\hline 1. Practical Costs & $2.55(2.31)$ & & 1.14 & 1.02 & .61 & .68 & 1.47 & .31 & .36 & 1.32 & .82 & 1.80 & 1.21 & 1.73 & 1.74 \\
\hline 2. Genetic Risk & $2.42(2.26)$ & & & .12 & 1.75 & .46 & .33 & 1.45 & 1.50 & .19 & .32 & .67 & .07 & .59 & .61 \\
\hline 3. Liver Functioning & $2.34(2.25)$ & & & & 1.63 & .34 & .45 & 1.33 & 1.38 & .31 & .20 & .79 & .19 & .71 & .72 \\
\hline 4. BAC & $2.06(2.31)$ & & & & & 1.29 & 2.08 & .30 & .25 & 1.93 & 1.43 & 2.42 & 1.82 & 2.34 & 2.35 \\
\hline 5. Risk Factors & $1.82(2.57)$ & & & & & & .79 & .99 & 1.04 & .64 & .14 & 1.12 & .53 & 1.05 & 1.06 \\
\hline 6. Cognitive Functioning & $1.73(2.53)$ & & & & & & & 1.78 & 1.83 & .14 & .65 & .34 & .26 & .26 & .28 \\
\hline 7. Descriptive Norm & $1.57(2.45)$ & & & & & & & & .05 & 1.64 & 1.13 & 2.12 & 1.52 & 2.04 & 2.07 \\
\hline 8. Consequences & $1.51(2.63)$ & & & & & & & & & 1.69 & 1.18 & 2.17 & 1.57 & 2.09 & 2.11 \\
\hline 9. Percentile Rank & $1.51(2.46)$ & & & & & & & & & & .51 & .48 & .12 & .40 & .42 \\
\hline 10. Reflective Norm & $1.18(2.52)$ & & & & & & & & & & & .99 & .39 & .91 & .92 \\
\hline 11. Profile & $0.58(2.44)$ & & & & & & & & & & & & .60 & .08 & .06 \\
\hline 12. Injunctive Norm & $0.22(0.63)$ & & & & & & & & & & & & & .52 & .54 \\
\hline 13. Didactic Information & $0.13(2.75)$ & & & & & & & & & & & & & & .02 \\
\hline 14. Strategies & $0.11(2.80)$ & & & & & & & & & & & & & & \\
\hline
\end{tabular}


Table 4

Differences in Affinity Factor Ratings between High-and Low-Risk College Student Drinkers

\begin{tabular}{|c|c|c|c|c|c|c|}
\hline \multirow[b]{2}{*}{ Feedback Components } & \multicolumn{3}{|c|}{ Novelty } & \multicolumn{3}{|c|}{ Interest } \\
\hline & $\begin{array}{l}\text { High-risk } \\
(n=228)\end{array}$ & $\begin{array}{l}\text { Low-risk } \\
(n=169) \\
\end{array}$ & $t(395)$ & $\begin{array}{l}\text { High-risk } \\
(n=228)\end{array}$ & $\begin{array}{l}\text { Low-risk } \\
(n=169) \\
\end{array}$ & $t(395)$ \\
\hline Practical Costs & $2.74(2.65)$ & $3.06(2.72)$ & 1.17 & $2.96(2.42)$ & $3.11(2.63)$ & .56 \\
\hline Liver Functioning & $2.30(2.73)$ & $3.02(2.56)$ & $2.67 * *$ & $2.59(2.45)$ & $3.21(2.21)$ & $2.60 *$ \\
\hline $\mathrm{BAC}$ & $2.40(2.69)$ & $2.99(2.58)$ & $2.19 *$ & $2.55(2.48)$ & $3.11(2.26)$ & $2.32 *$ \\
\hline Risk Factors & $1.55(3.08)$ & $2.54(2.82)$ & $3.29 * *$ & $2.04(2.78)$ & $2.88(2.45)$ & $3.21 * *$ \\
\hline Consequences & $.79(3.40)$ & $.90(3.48)$ & .33 & $1.73(2.94)$ & $1.97(3.00)$ & .79 \\
\hline Percentile Ranking & $2.07(2.78)$ & $2.67(2.63)$ & $2.17 *$ & $2.09(2.62)$ & $2.66(2.63)$ & $2.16^{*}$ \\
\hline Reflective Norm & $1.73(2.77)$ & $2.35(2.83)$ & $2.18 *$ & $1.80(2.83)$ & $2.64(2.53)$ & $3.04 * *$ \\
\hline Profile & $.03(3.17)$ & $.48(3.56)$ & 1.36 & $1.00(2.93)$ & $1.34(3.15)$ & 1.10 \\
\hline Injunctive Norm & $.67(3.34)$ & $1.85(3.09)$ & $3.62 * * *$ & $1.57(2.96)$ & $2.47(2.64)$ & $3.14 * *$ \\
\hline Didactic Info & $-.82(3.49)$ & $.05(3.73)$ & $2.37 *$ & $.80(3.22)$ & $1.81(2.96)$ & $3.24 * *$ \\
\hline
\end{tabular}

Note. Norm $=$ Normative comparison. Scores ranged from -5 to 5 , with higher scores indicating higher ratings of novelty and interest. ${ }^{*} p$ $<.05, * * p<.01, * * * p<.001$ 
Differences in Affinity Factor Ratings between High- and Low-Risk College Student Drinkers

\begin{tabular}{|c|c|c|c|c|c|c|}
\hline \multirow[b]{2}{*}{ Feedback Components } & \multicolumn{3}{|c|}{ Personal Relevance } & \multicolumn{3}{|c|}{ Impact on Motivation to change } \\
\hline & $\begin{array}{l}\text { High-risk } \\
(n=228)\end{array}$ & $\begin{array}{l}\text { Low-risk } \\
(n=169)\end{array}$ & $t(395)$ & $\begin{array}{l}\text { High-risk } \\
(n=228)\end{array}$ & $\begin{array}{l}\text { Low-risk } \\
(n=169)\end{array}$ & $t(395)$ \\
\hline Practical Costs & $2.71(2.62)$ & $3.05(2.62)$ & 1.29 & $2.19(2.85)$ & $2.85(2.70)$ & $2.31 *$ \\
\hline Genetic Risk & $2.58(2.56)$ & $3.08(2.62)$ & 1.90 & $1.99(2.86)$ & $2.69(2.75)$ & $2.46^{* *}$ \\
\hline Liver Functioning & $2.45(2.48)$ & $3.08(2.48)$ & $2.51 * *$ & $2.26(2.70)$ & $2.96(2.48)$ & $2.63 * *$ \\
\hline BAC & $2.33(2.62)$ & $2.79(2.63)$ & 1.72 & $1.61(2.91)$ & $2.59(2.85)$ & $3.32 * *$ \\
\hline Risk Factors & $1.96(2.94)$ & $2.78(2.73)$ & $2.81 * *$ & $1.85(2.90)$ & $2.78(2.54)$ & $3.33 * *$ \\
\hline Cognitive Functioning & $2.06(2.81)$ & $2.59(2.75)$ & 1.87 & $1.27(3.13)$ & $2.33(2.86)$ & $3.52 * * *$ \\
\hline Descriptive Norm & $1.64(2.78)$ & $2.22(3.05)$ & $1.99 *$ & $1.08(3.34)$ & $2.65(2.76)$ & $5.11 * * *$ \\
\hline Consequences & $1.92(2.95)$ & $2.66(2.67)$ & $2.57 *$ & $1.58(3.05)$ & $2.45(2.76)$ & $2.97 * *$ \\
\hline Percentile Rank & $1.61(2.93)$ & $2.19(3.05)$ & 1.92 & $.97(3.27)$ & $2.46(2.92)$ & $4.78 * * *$ \\
\hline Reflective Norm & $1.19(3.02)$ & $1.92(2.94)$ & $2.40 *$ & $.64(3.17)$ & $1.87(3.04)$ & $3.88 * * *$ \\
\hline Profile & $1.20(2.84)$ & $1.09(3.44)$ & -.34 & $.39(3.35)$ & $1.91(3.05)$ & $4.71 * * *$ \\
\hline Injunctive Norm & $1.40(3.20)$ & $2.22(2.99)$ & $2.60 *$ & $1.07(3.20)$ & $2.38(2.94)$ & $4.24 * * *$ \\
\hline Didactic Info & $1.03(3.13)$ & $1.82(2.79)$ & $2.63^{* *}$ & $-.22(3.28)$ & $1.11(3.28)$ & $4.00 * * *$ \\
\hline Strategies & $1.21(3.08)$ & $1.85(2.77)$ & $2.16^{*}$ & $-.53(3.34)$ & $.88(3.25)$ & $4.20 * * *$ \\
\hline
\end{tabular}

Note. Norm $=$ Normative comparison. Scores ranged from -5 to 5 , with higher scores indicating higher ratings of novelty and interest. $* p$ $<.05, * * p<.01, * * * p<.001$ 
Differences in Affinity Factor Ratings between High- and Low-Risk College Student Drinkers

\begin{tabular}{|c|c|c|c|c|c|c|}
\hline \multirow[b]{2}{*}{ Feedback Components } & \multicolumn{3}{|c|}{ Impact on Intent to Change } & \multicolumn{3}{|c|}{ Skepticism } \\
\hline & $\begin{array}{l}\text { High-risk } \\
(n=228)\end{array}$ & $\begin{array}{l}\text { Low-risk } \\
(n=169)\end{array}$ & $t(395)$ & $\begin{array}{l}\text { High-risk } \\
(n=228)\end{array}$ & $\begin{array}{l}\text { Low-risk } \\
(n=169)\end{array}$ & $t(395)$ \\
\hline Practical Costs & $2.15(2.86)$ & $2.83(2.71)$ & $2.41 * *$ & $-1.34(3.06)$ & $-1.18(3.17)$ & .51 \\
\hline Genetic Risk & $1.94(2.92)$ & $2.67(2.86)$ & $2.47 * *$ & $-.92(2.98)$ & $-.89(3.44)$ & .09 \\
\hline Liver Functioning & $2.10(2.75)$ & $2.91(2.55)$ & $3.00 * *$ & $-1.22(2.83)$ & $-1.36(3.13)$ & -.46 \\
\hline BAC & $1.42(2.95)$ & $2.49(2.88)$ & $3.61 * * *$ & $-.43(3.01)$ & $-.69(3.19)$ & -.85 \\
\hline Risk Factors & $1.69(2.97)$ & $2.78(2.58)$ & $3.79 * * *$ & $-1.16(2.84)$ & $-.86(3.16)$ & 1.01 \\
\hline Cognitive Functioning & $1.23(3.15)$ & $2.46(2.79)$ & $4.11 * * *$ & $-1.01(2.93)$ & $-1.04(3.23)$ & -.09 \\
\hline Descriptive Norm & $.93(3.35)$ & $2.63(2.82)$ & $5.48 * * *$ & $.13(2.79)$ & $.01(3.09)$ & -.39 \\
\hline Consequences & $1.53(3.03)$ & $2.28(2.90)$ & $2.49 * *$ & $-1.32(2.90)$ & $-1.24(3.14)$ & .27 \\
\hline Percentile Rank & $.80(3.26)$ & $2.27(2.91)$ & $4.73 * * *$ & $.13(2.90)$ & $.24(2.98)$ & .39 \\
\hline Reflective Norm & $.54(3.18)$ & $1.74(3.14)$ & $3.75 * * *$ & $.12(2.95)$ & $-.19(3.20)$ & -1.01 \\
\hline Profile & $.30(3.29)$ & $1.90(3.06)$ & $4.99 * * *$ & $-.43(2.79)$ & $-.15(3.07)$ & .94 \\
\hline Injunctive Norm & $1.14(3.20)$ & $2.43(2.85)$ & $4.22 * * *$ & -.34 (2.99) & $-.05(3.18)$ & .93 \\
\hline Didactic Info & $-.16(3.25)$ & $1.07(3.33)$ & $3.66 * * *$ & $-1.64(2.90)$ & $-1.22(3.16)$ & 1.36 \\
\hline Strategies & $-.31(3.25)$ & $1.01(3.19)$ & $4.01 * * *$ & $-1.66(2.86)$ & $-1.60(2.90)$ & .19 \\
\hline
\end{tabular}

Note. Norm $=$ Normative comparison. Scores ranged from -5 to 5 , with higher scores indicating higher ratings of novelty and interest. $* p$ $<.05, * * p<.01, * * * p<.001$ 
Table 5

Differences in Affinity and Skepticism between Women $(n=162)$ and Men $(n=235)$ after Controlling for Binge Drinking

\begin{tabular}{|c|c|c|c|c|c|c|c|c|c|c|}
\hline \multirow[b]{3}{*}{ Feedback Component } & \multicolumn{4}{|c|}{ Affinity } & \multirow[b]{3}{*}{$F(2,394)$} & \multicolumn{4}{|c|}{ Skepticism } & \multirow[b]{3}{*}{$t(395)$} \\
\hline & \multicolumn{2}{|c|}{ Women } & \multicolumn{2}{|c|}{ Men } & & \multicolumn{2}{|c|}{ Women } & \multicolumn{2}{|c|}{ Men } & \\
\hline & $M$ & $S D$ & $M$ & $S D$ & & $M$ & $S D$ & $M$ & $S D$ & \\
\hline Practical Costs & 3.30 & 2.22 & 1.91 & 2.23 & $36.72 * * *$ & -1.65 & 3.07 & -.72 & 3.07 & $-2.95 * *$ \\
\hline Genetic Risk & 3.05 & 2.21 & 2.10 & 2.21 & $17.23 * * *$ & -1.35 & 3.18 & -.26 & 3.07 & $-3.40^{* * *}$ \\
\hline Liver Functioning & 2.95 & 2.16 & 2.18 & 2.18 & $12.15^{* *}$ & -1.46 & 2.99 & -1.02 & 2.91 & -1.48 \\
\hline $\mathrm{BAC}$ & 2.68 & 2.21 & 1.93 & 2.21 & $10.78 * *$ & -.66 & 3.11 & -.36 & 3.06 & -.97 \\
\hline Risk Factors & 2.50 & 2.41 & 1.81 & 2.42 & $7.64 * *$ & -1.17 & 2.95 & -.84 & 3.02 & -1.07 \\
\hline Cognitive Functioning & 2.53 & 2.39 & 1.48 & 2.39 & $18.34 * * *$ & -1.42 & 3.03 & -.45 & 3.00 & $-3.15 * *$ \\
\hline Descriptive Norm & 2.54 & 2.25 & 1.26 & 2.25 & $30.48 * * *$ & .05 & 3.03 & .12 & 2.75 & -.26 \\
\hline Consequences & 2.13 & 2.58 & 1.18 & 2.58 & $12.85 * * *$ & -1.50 & 3.00 & -.99 & 2.99 & -1.67 \\
\hline Percentile Rank & 2.39 & 2.28 & 1.21 & 2.29 & $25.44 * * *$ & .06 & 2.98 & .34 & 2.85 & -.92 \\
\hline Reflective Norm & 1.90 & 2.45 & 1.09 & 2.47 & $10.19 * *$ & -.22 & 3.14 & .30 & 2.92 & -1.66 \\
\hline Profile & 1.34 & 2.36 & .28 & 2.38 & $18.74 * * *$ & -.37 & 2.88 & -.24 & 2.96 & -.42 \\
\hline Injunctive Norm & .40 & .58 & .23 & .59 & $8.79 * *$ & -.32 & 3.06 & -.06 & 3.09 & -.85 \\
\hline Didactic Information & .90 & 2.71 & .10 & 2.72 & $8.21 * *$ & -1.65 & 2.98 & -1.19 & 3.05 & -1.50 \\
\hline Strategies & .84 & 2.73 & .08 & 2.75 & $7.33 * *$ & -1.89 & 2.85 & -1.26 & 2.88 & $-2.17 *$ \\
\hline Overall Affinity & 2.22 & 1.76 & 1.27 & 1.77 & $27.02 * * *$ & & & & & \\
\hline
\end{tabular}

Note. Scores ranged from -5 to 5 , with higher scores indicating stronger affinity. $* p<.05, * * p<.01, * * * p<.001$ 
Table 6

Student Preferences for Feedback Components

\begin{tabular}{|c|c|c|c|c|c|c|c|}
\hline & $\begin{array}{l}\text { Total sample } \\
\quad(N=397)\end{array}$ & $\begin{array}{l}\text { High-risk } \\
\text { drinkers } \\
(n=228) \\
\end{array}$ & $\begin{array}{c}\text { Low-risk } \\
\text { drinkers } \\
(n=169) \\
\end{array}$ & $\begin{array}{l}\text { Females } \\
(n=235)\end{array}$ & $\begin{array}{c}\text { Males } \\
(n=162)\end{array}$ & $\begin{array}{c}\text { Social } \\
\text { drinkers } \\
(n=70)\end{array}$ & $\begin{array}{c}\text { Non-social } \\
\text { drinkers } \\
(n=80)\end{array}$ \\
\hline Age, $M(S D)$ & $19.93(1.84)$ & $19.93(1.84)$ & $19.93(1.84)$ & $19.81(1.67)$ & $20.10(2.06)$ & $19.81(1.58)$ & $19.94(2.08)$ \\
\hline$n=$ male $(\%)$ & $162(41 \%)$ & $111(49 \%)$ & $51(30 \%)$ & N/A & N/A & $33(47 \%)$ & $26(33 \%)$ \\
\hline \multicolumn{8}{|l|}{ Student Preferences } \\
\hline Descriptive Norms & $394(58 \%)$ & $125(55 \%)$ & $104(62 \%)$ & $147(63 \%)^{\mathrm{a}}$ & $82(52 \%)^{\mathrm{a}}$ & $40(57 \%)$ & $43(54 \%)$ \\
\hline Risk Factors & $131(33 \%)$ & $79(35 \%)$ & $52(31 \%)$ & $73(31 \%)$ & $58(36 \%)$ & $24(34 \%)$ & $26(33 \%)$ \\
\hline Injunctive Norms & $125(32 \%)$ & $66(29 \%)$ & $59(35 \%)$ & $77(33 \%)$ & $48(30 \%)$ & $18(26 \%)$ & $28(35 \%)$ \\
\hline Consequences & $108(27 \%)$ & $58(25 \%)$ & $50(30 \%)$ & $65(28 \%)$ & $43(27 \%)$ & $18(26 \%)$ & $32(40 \%)$ \\
\hline Reflective Norms & $107(27 \%)$ & $61(27 \%)$ & $46(27 \%)$ & $57(24 \%)$ & $50(31 \%)$ & $20(29 \%)$ & $24(30 \%)$ \\
\hline Didactics & $71(18 \%)$ & $42(18 \%)$ & $29(17 \%)$ & $45(19 \%)$ & $26(16 \%)$ & $13(19 \%)$ & $15(19 \%)$ \\
\hline Strategies & $49(12 \%)$ & $26(12 \%)$ & $23(14 \%)$ & $30(13 \%)$ & $19(12 \%)$ & $12(17 \%)$ & $10(13 \%)$ \\
\hline
\end{tabular}

${ }^{\mathrm{a}} \chi^{2}(1)=4.70, p=.03 ;{ }^{\mathrm{b}} \chi^{2}(1)=6.46, p=.01$. 


\section{VITA}

Mary Beth Miller

Candidate for the Degree of

Master of Science

Thesis: WHAT DO COLLEGE STUDENT DRINKERS WANT TO KNOW? STUDENT PERCEPTIONS OF ALCOHOL-RELATED FEEDBACK

Major Field: Psychology

\section{Biographical:}

\section{Education:}

Completed the requirements for the Master of Science in Psychology at Oklahoma State University, Stillwater, Oklahoma in May of 2012.

Completed the requirements for the Bachelor of Arts in Psychology and Spanish at Westminster College, Fulton, Missouri in May of 2009.

\section{Experience:}

Behavior Change Laboratory, Oklahoma State University, Stillwater, OK, 2010 - Present

Department of Pediatrics, University of Oklahoma Health Sciences Center, Oklahoma City, OK, August 2011

Fulton State Hospital, University of Missouri-Columbia, Columbia, MO, May - August 2009

\section{Current Professional Memberships:}

Association for Behavioral and Cognitive Therapies (ABCT), 2011

Addictive Behaviors Special Interest Group (AB SIG)

American Psychological Association (APA), 2011

Oklahoma Psychological Association (OPA), 2010

Oklahoma Psychological Association Student Society (OPASS)

Graduate and Professional Student Government Association (GPSGA), 2010

Psychology Graduate Student Association (PGSA), 2010

Omicron Delta Kappa (ODK), National Leadership Society, 2008 
Title of Study: WHAT DO COLLEGE STUDENT DRINKERS WANT TO KNOW? STUDENT PERCEPTIONS OF ALCOHOL-RELATED FEEDBACK

Pages in Study: 65

Candidate for the Degree of Master of Science

Major Field: Psychology

Scope and Method of Study:

Currently, there is little information available guiding which components to include in personalized feedback interventions. The present research examined the way in which students respond to the different feedback components presented in such interventions. Undergraduate student drinkers $(N=397,41 \%$ male) rated their affinity for and skepticism of 14 feedback components and identified the three types of information that they preferred above all others.

Findings and Conclusions:

The majority of students preferred information regarding descriptive normative comparisons and the practical costs of drinking, while few reported a desire to learn behavioral strategies to limit risk or didactic information. High-risk drinkers $(n=228)$ reported lower ratings for all feedback components than did low-risk drinkers, and men provided significantly lower ratings for all feedback components than did women. This is the first study to document student preferences for the different feedback components commonly included in personalized feedback interventions. The current study generates hypotheses regarding methods and components that may increase the efficacy of current feedback interventions for high-risk drinking. 